\title{
Using sonic anemometer temperature to measure sensible heat flux in strong winds
}

\author{
S. P. Burns ${ }^{1,3}$, T. W. Horst ${ }^{1}$, L. Jacobsen ${ }^{2}$, P. D. Blanken ${ }^{3}$, and R. K. Monson ${ }^{4}$ \\ ${ }^{1}$ National Center for Atmospheric Research, Boulder, Colorado, USA \\ ${ }^{2}$ Campbell Scientific, Inc., Logan, Utah, USA \\ ${ }^{3}$ Department of Geography, University of Colorado, Boulder, USA \\ ${ }^{4}$ School of Natural Resources and the Environment, University of Arizona, Tucson, USA
}

Correspondence to: S. P. Burns (sean@ucar.edu)

Received: 2 December 2011 - Published in Atmos. Meas. Tech. Discuss.: 12 January 2012

Revised: 16 August 2012 - Accepted: 16 August 2012 - Published: 3 September 2012

\begin{abstract}
Sonic anemometers simultaneously measure the turbulent fluctuations of vertical wind $\left(w^{\prime}\right)$ and sonic temperature $\left(T_{\mathrm{s}}^{\prime}\right)$, and are commonly used to measure sensible heat flux $(H)$. Our study examines 30-min heat fluxes measured with a Campbell Scientific CSAT3 sonic anemometer above a subalpine forest. We compared $H$ calculated with $T_{\mathrm{s}}$ to $H$ calculated with a co-located thermocouple and found that, for horizontal wind speed $(U)$ less than $8 \mathrm{~m} \mathrm{~s}^{-1}$, the agreement was around $\pm 30 \mathrm{~W} \mathrm{~m}^{-2}$. However, for $U>\approx 8 \mathrm{~m} \mathrm{~s}^{-1}$, the CSAT $H$ had a generally positive deviation from $H$ calculated with the thermocouple, reaching a maximum difference of $\approx 250 \mathrm{~W} \mathrm{~m}^{-2}$ at $U \approx 18 \mathrm{~m} \mathrm{~s}^{-1}$. With version 4 of the CSAT firmware, we found significant underestimation of the speed of sound and thus $T_{\mathrm{S}}$ in high winds (due to a delayed detection of the sonic pulse), which resulted in the large CSAT heat flux errors. Although this $T_{\mathrm{S}}$ error is qualitatively similar to the well-known fundamental correction for the crosswind component, it is quantitatively different and directly related to the firmware estimation of the pulse arrival time. For a CSAT running version 3 of the firmware, there does not appear to be a significant underestimation of $T_{\mathrm{s}}$; however, a $T_{\mathrm{s}}$ error similar to that of version 4 may occur if the CSAT is sufficiently out of calibration. An empirical correction to the CSAT heat flux that is consistent with our conceptual understanding of the $T_{\mathrm{S}}$ error is presented. Within a broader context, the surface energy balance is used to evaluate the heat flux measurements, and the usefulness of sideby-side instrument comparisons is discussed.
\end{abstract}

\section{Introduction}

Sonic anemometers have been used to measure threedimensional wind vectors, temperature, and surface sensible heat and momentum fluxes since the early 1960s. They have played a pivotal role in studying the surface energy balance (SEB), which describes how the radiative energy at the Earth's surface is partitioned between latent heat flux (LE) and sensible heat flux $(H)$ (Stewart and Thom, 1973; Garratt, 1992; Blanken et al., 1997; Oncley et al., 2007; Foken, 2008a). Despite improvements in instrumentation accuracy, most flux-measuring sites find that the measured sensible and latent heat fluxes only account for $\approx 80 \%$ of the available incoming energy (Wilson et al., 2002; Foken, 2008a). The so-called "energy balance closure problem" has recently been reviewed (Foken et al., 2011; Leuning et al., 2012), and the imbalance is often attributed to phenomena that are not properly measured by the eddy covariance technique (e.g., horizontal heat advection, low-frequency flux contributions from heterogeneous landscapes, effects of sloped terrain on the radiation measurements, and thermal lags between the various terms within the energy budget, etc). The energy balance closure typically improves under windy/turbulent conditions when the ground and atmosphere are "well-coupled" (Franssen et al., 2010). Spatially homogeneous and moisturelimited environments such as deserts appear to be optimal for successfully closing the energy budget (Timouk et al., 2009; Foken, 2008a). Any errors in the eddy covariance instruments (such as sonic anemometers) are believed to result in an underestimation of the fluxes due to missing 
high-frequency response or averaging periods that are too short (Leuning et al., 2012).

Previous studies have shown that sonic anemometers result in erroneous sensible heat flux measurements during high winds (Grelle and Lindroth, 1996; Aubinet et al., 2000; Smedman et al., 2007). Grelle and Lindroth (1996) used a Gill Solent R2 and concluded that strong winds caused deformation of the supports holding the sonic transducers and resulted in high-frequency noise that made an accurate heat flux measurement impossible. As an alternative, they calculated $H$ using a co-located fast-response $0.025 \mathrm{~mm}$ platinum wire resistance thermometer (PRT). The study by Smedman et al. (2007) used two co-located Gill Solent models R2 and R3 sonic anemometers and found that, independent of stability conditions, sonic-measured heat flux had a larger magnitude than $H$ with an alternative temperature sensor. Grelle and Lindroth (1996) also tested three other models of sonic anemometers and found similar problems for wind speeds faster than $10 \mathrm{~m} \mathrm{~s}^{-1}$. Recent heat flux comparisons between a Solent R3 and an independent $0.1 \mathrm{~mm}$ diameter PRT have shown good agreement (e.g., Grelle and Burba, 2007), though we should note that the Grelle and Burba measurements were at a height of only $4 \mathrm{~m}$ and might not have experienced strong winds. Another issue with using sonic anemometers in cold, windy places is that blowing snow can drift between the sonic transducers which causes spikes in the sonic temperature (Foken, 1998) and results in an overestimation of heat flux as well as misleading flux directions depending on whether the snow particle is moving upward or downward in the the path (Lüers and Bareiss, 2011).

This paper uses a Campbell Scientific CSAT3 sonic anemometer (hereafter "CSAT"; Campbell Scientific, Inc., 2010) at the Niwot Ridge Subalpine Forest AmeriFlux site (NWT) to examine the sensible heat flux in strong winds. Turnipseed et al. (2002) studied the energy balance at the NWT site and found that, during the daytime, the sum of the turbulent fluxes equals $80-90 \%$ of the radiative energy input into the forest. At night, under moderately turbulent conditions, the energy balance closure is comparable to the daytime. However, when the nighttime conditions are either calm or extremely turbulent, the sensible and latent heat fluxes only equal $20-60 \%$ of the net longwave radiative flux. Turnipseed et al. (2002) discussed several possible reasons for this nighttime discrepancy (e.g., instrument error, footprint mismatch, horizontal advection), but none of these reasons could adequately explain the fact that the nighttime imbalance existed in the presence of strong winds. They concluded that the sonic temperature did not have sufficient resolution to capture the small temperature fluctuations, which led to inaccurate sensible heat fluxes.

In early 2008 the sonic anemometers at NWT were recalibrated (details in Sect. 2.3). After the recalibration, the new sensible heat flux still did not improve the agreement between the daytime and nocturnal energy balance in windy conditions, and the imbalance was even more dramatic than before the recalibration. The goals of the current study are to (1) describe the discrepancy observed in the calculated sensible heat flux, (2) compare the heat flux calculated using sonic temperature to that calculated with a co-located thermocouple, (3) present independent wind-tunnel results that attempt to explain the tower observations, (4) briefly describe Campbell Scientific, Inc. testing of the CSAT, (5) present a conceptual model of the CSAT error and suggest an empirical correction method to the CSAT heat flux, and (6) re-visit the surface energy balance results from Turnipseed et al. (2002) in light of the results from items (1)-(5).

\section{Data and methods}

\subsection{Site description}

This study uses data from the Niwot Ridge Subalpine Forest Ameriflux site which is located below Niwot Ridge, Colorado, $8 \mathrm{~km}$ east of the Continental Divide $\left(40^{\circ} 1^{\prime} 58^{\prime \prime} \mathrm{N}\right.$, $105^{\circ} 32^{\prime} 47^{\prime \prime} \mathrm{W}, 3050 \mathrm{~m}$ elevation). The NWT measurements started in November 1998 as described in Monson et al. (2002) and Turnipseed et al. (2002, 2003). The tree density around the NWT Tower is $\approx 0.4$ trees $\mathrm{m}^{-2}$ with a leaf area index (LAI) of $3.8-4.2 \mathrm{~m}^{2} \mathrm{~m}^{-2}$ and tree heights of $12-$ $13 \mathrm{~m}$ (Turnipseed et al., 2002). In winter, NWT is a dry and windy place. Between November-February, the 30-min average $21.5 \mathrm{~m}$ wind speed $(U)$ is around $7 \mathrm{~m} \mathrm{~s}^{-1}$ (standard deviation $\approx 4.5 \mathrm{~m} \mathrm{~s}^{-1}$ ) with a maximum near $20 \mathrm{~m} \mathrm{~s}^{-1}$. Typical wintertime mid-day sensible heat flux values are on the order of $200 \mathrm{~W} \mathrm{~m}^{-2}$, while latent heat flux is usually less than $40 \mathrm{~W} \mathrm{~m}^{-2}$ (Turnipseed et al., 2002). On top of Niwot Ridge (i.e., above tree-line), blowing snow is common (Berg, 1986) and snow/ice particles are often blown downslope over the forest. More information on NWT is available on-line at http://public.ornl.gov/ameriflux/.

\subsection{Sonic anemometer thermometry}

A few of the important relationships related to sonic anemometer thermometry are summarized here; a more complete description of the technology is readily available (e.g., Kaimal and Businger, 1963; Schotanus et al., 1983; Kaimal and Gaynor, 1991; Foken, 2008b, and many others).

The relationship between air temperature $(T)$, the speed of sound $(c)$, and specific humidity $(q)$ within the atmosphere is well-known:

$T=\frac{c^{2}}{\gamma_{\mathrm{d}} R_{\mathrm{d}}}\left(\frac{1}{1+0.51 q}\right)$

where $\gamma_{\mathrm{d}}=c_{\mathrm{pa}} / c_{\mathrm{va}}=1.4$ is the dry air specific heat ratio, $c_{\mathrm{pa}}$ and $c_{\mathrm{va}}$ are the dry air specific heat at constant pressure and volume $\left(\mathrm{J} \mathrm{kg}^{-1} \mathrm{~K}^{-1}\right)$, and $R_{\mathrm{d}}$ is the gas constant for dry air $\left(287 \mathrm{~J} \mathrm{~kg}^{-1} \mathrm{~K}^{-1}\right)$.

A sonic anemometer-thermometer sequentially transmits and receives sound pulses between two transducers separated 
by a path-length distance $(d)$. The speed of sound is determined from the measured times to transit $d$ ( $t_{1}$ in one direction and $t_{2}$ in the opposite direction) and the geometry of the sound rays, such that

$$
\frac{1}{t_{1}}+\frac{1}{t_{2}}=\frac{2 c \cos (\alpha)}{d}=\frac{2}{d} \sqrt{c^{2}-V_{n}^{2}}
$$

where $V_{n}$ is the wind component perpendicular to $d$ (i.e., cross-wind) and $\alpha=\sin ^{-1}\left(V_{n} / c\right)$ is the deflection angle of the sound ray off the transducer-path axis. Solving Eq. (2) for $c$ and substituting it into Eq. (1) with $q=0$, it follows that sonic temperature $\left(T_{\mathrm{S}}\right)$ is

$T_{\mathrm{s}} \equiv \frac{c^{2}}{\gamma_{\mathrm{d}} R_{\mathrm{d}}}=\frac{1}{\gamma_{\mathrm{d}} R_{\mathrm{d}}}\left[\left(\frac{d}{2}\right)^{2}\left(\frac{1}{t_{1}}+\frac{1}{t_{2}}\right)^{2}+V_{n}^{2}\right]$.

In a moist atmosphere, air temperature is calculated from $T_{\mathrm{S}}$ as

$$
T_{\mathrm{s}}^{\text {air }}=\frac{T_{\mathrm{s}}}{1+0.51 q} .
$$

To determine the sonic-derived sensible heat flux $H$, we assume $\left(T_{\mathrm{S}}^{\text {air }}\right)^{\prime}=T^{\prime}$, multiply each side of Eq. (4) by the vertical wind component $w$, decompose the measured variables into mean and fluctuating components (i.e., $T_{\mathrm{S}}=\overline{T_{\mathrm{S}}}+T_{\mathrm{S}}^{\prime}$, etc.), and perform Reynolds averaging. Neglecting higher-order terms (e.g., Fuehrer and Friehe, 2002) leads to

$$
\begin{aligned}
\frac{H}{\bar{\rho} \overline{c_{\mathrm{p}}}} & =\overline{w^{\prime} T^{\prime}}=\left[\overline{w^{\prime}\left(T_{\mathrm{s}}^{\mathrm{uc}}\right)^{\prime}}+2 \frac{\bar{T} \bar{u}}{\overline{c^{2}}} \overline{u^{\prime} w^{\prime}}-0.51 \bar{T} \overline{w^{\prime} q^{\prime}}\right] \\
& =\left[\overline{w^{\prime} T_{\mathrm{s}}^{\prime}}-0.51 \bar{T} \overline{w^{\prime} q^{\prime}}\right],
\end{aligned}
$$

where $\rho$ is the air density $\left(\mathrm{kg} \mathrm{m}^{-3}\right), c_{\mathrm{p}}$ is the specific heat of moist air at constant pressure, and $u$ is the horizontal wind component in streamwise coordinates (note that $\bar{\rho}=\overline{\rho_{\mathrm{a}}}+\overline{\rho_{\mathrm{v}}}$ and $\overline{c_{\mathrm{p}}}=\left(\overline{\rho_{\mathrm{a}}} c_{\mathrm{pa}}+\overline{\rho_{\mathrm{v}}} c_{\mathrm{pv}}\right) / \bar{\rho}$ where the subscripts "a" and "v" refer to dry air and water vapor, respectively). $T_{\mathrm{S}}^{\mathrm{uc}}$ is $T_{\mathrm{S}}$ without the cross-wind correction (i.e., $\left.T_{\mathrm{s}}^{\mathrm{uc}}=T_{\mathrm{s}}-V_{n}^{2}\left(\gamma_{\mathrm{d}} R_{\mathrm{d}}\right)^{-1}\right)$. The $\overline{u^{\prime} w^{\prime}}$ term is the socalled cross-wind correction term, but most modern sonic anemometers take this into account with internal processing software that corrects each individual $T_{\mathrm{S}}$ sample for crosswind effects using Eq. (3) (Hignett, 1992). The implementation of Eq. (3) varies depending on the sonic anemometer manufacturer, model, and signal-processing firmware (Loescher et al., 2005; Campbell Scientific, Inc., 2010).

\subsection{Energy balance equation and instrumentation}

If we neglect the vertical advection of heat, the terms in the surface energy balance are

$R_{\mathrm{a}}=R_{\text {net }}-G_{z}-S_{\text {soil }}-S_{\text {canopy }}=H+\mathrm{LE}+H_{\mathrm{adv}}$,

where $R_{\mathrm{a}}$ is the available energy. At NWT, net radiation $\left(R_{\text {net }}\right)$ was measured at $z \approx 25 \mathrm{~m}$ above the ground with both a net (Radiation and Energy Balance Systems REBS, model Q*7.1) and a four-component (Kipp and Zonen, model CNR1) radiometer. The heat flux at the soil surface $(G)$ is determined from the soil heat flux $\left(G_{z}\right)$ measured at depth $z$ and the heat stored in the overlying soil layer $\left(S_{\text {soil }}\right)$. Canopy storage ( $\left.S_{\text {canopy }}\right)$ accounts for heat stored in the biomass between the ground and sensible heat flux measurement level. $S_{\text {canopy }}$ and $S_{\text {soil }}$ are typically less than $10 \%$ of $R_{\text {net }}$ (Oncley et al., 2007). At NWT, $G_{z}$ was measured with multiple soil heat flux plates (REBS, model HFT-1) at a depth of $10 \mathrm{~cm}$, and Turnipseed et al. (2002) showed that the storage terms and $G_{z}$ were small (less than $8 \%$ of $R_{\text {net }}$ ). Therefore, we neglect $S_{\text {canopy }}$ and $S_{\text {soil }}$ and assume the surface heat flux is close to our measured soil heat flux (i.e., $G \approx G_{z}$ ). The horizontal advection of heat $\left(H_{\text {adv }}\right)$ requires spatially distributed measurements, and is thought to be a primary reason that Eq. (6) does not balance at most flux sites (Leuning et al., 2012). In our discussions, the simple SEB closure fraction will be designated as CF (e.g., Barr et al., 2006) and refers to the ratio of the sum of the turbulent fluxes to $\left(R_{\text {net }}-G\right)$, i.e., $\mathrm{CF} \equiv(H+\mathrm{LE}) /\left(R_{\text {net }}-G\right)$. Similarly to Turnipseed et al. (2002), we find nocturnal CF with $R_{\text {net }}$ from the Q*7.1 sensor is about $15 \%$ closer to closing the SEB than with the CNR1 sensor (see Burns et al., 2012 for details). For simplicity, only results with the $\mathrm{Q} * 7.1 R_{\text {net }}$ sensor are presented here.

Latent and sensible heat flux were measured at $z \approx 21.5 \mathrm{~m}$ with a CSAT providing the high-frequency vertical wind $\left(w^{\prime}\right)$ and temperature $\left(T_{\mathrm{s}}^{\prime}\right)$ fluctuations, while water vapor $\left(q^{\prime}\right)$ was measured with a co-located krypton hygrometer (Turnipseed et al., 2002). The $21.5 \mathrm{~m} \mathrm{CSAT}$ was oriented so the alongsonic axis was pointed $203^{\circ}$ from true north. Strong winds at NWT are almost exclusively from the west (e.g., Burns et al., 2011) so that the angle between the wind vector and CSAT axis was $\approx 67^{\circ}$, well within the CSAT $\pm 170^{\circ}$ acceptance angle and also avoiding influence of the tower structure (Friebel et al., 2009). Winds are rotated from sonic to planar-fit streamwise coordinates prior to the flux calculations (Wilczak et al., 2001). $T_{\mathrm{S}}$ output by a CSAT is an average from the three non-orthogonal paths. We use " $H_{\text {CSAT" }}$ to designate the heat flux calculated with $T_{\mathrm{s}}$ following Eq. (5).

The CSAT operates with either embedded-code firmware version 3 or version 4 (hereafter, ver3 and ver4) and uses advanced digital signal processing to determine the ultrasonic times of flight (i.e., $t_{1}$ and $t_{2}$ in Eq. 3). Ver4 is designed to produce usable results when the signal is weak such as when liquid water is on the transducers, but degrades the $T_{\mathrm{S}}$ resolution from $0.002 \mathrm{~K}$ in ver3 to $0.03 \mathrm{~K}$ in ver4 (see Campbell Scientific, Inc., 2010 for more details about ver3 versus ver4). The CSAT diagnostic flag is an indicator of potential spikes in the sonic data (Campbell Scientific, Inc., 2010). The number of spikes in sonic anemometer data has been found to increase non-linearly with increasing wind speed (Laubach, 1995; Foken, 1998; Lüers and Bareiss, 2011). Consistent with these previous studies, we found that low wind speed 
Table 1. A summary of NWT AmeriFlux tower temperature measurements used in our study.

\begin{tabular}{|c|c|c|c|c|c|c|c|}
\hline Sensor & Acronym & $\begin{array}{l}\text { Serial } \\
\text { No. }\end{array}$ & $\begin{array}{l}\text { Sensor } \\
\text { Height } \\
(\mathrm{cm})\end{array}$ & $\begin{array}{l}\text { Horiz. } \\
\text { Dist. }^{a} \\
(\mathrm{~cm})\end{array}$ & $\begin{array}{l}\text { Sample } \\
\text { Rate }^{\text {b }}\end{array}$ & $\begin{array}{l}\text { Deployment } \\
\text { Dates }\end{array}$ & $\begin{array}{l}\text { CSAT Factory Calibration } \\
\text { Date (F-CAL) and/or } \\
\text { Additional Comments }\end{array}$ \\
\hline $\begin{array}{l}\text { Vaisala } \\
\text { HMP35-D }\end{array}$ & $T_{\text {asp }}$ & & 2150 & $\approx 90$ & 1 & 1 Nov 1998-present & $\begin{array}{l}\text { slow-response platinum resistance } \\
\text { thermometer in a mechanically } \\
\text { aspirated housing }\end{array}$ \\
\hline E-type & $T_{\mathrm{tc}}(\mathrm{Far})$ & & 2198 & $\approx 136$ & 1 & 20 Aug 2002-present & wire dia $=0.254 \mathrm{~mm}$, unaspirated \\
\hline Thermocouple & $T_{\mathrm{tc}}(\mathrm{Near})$ & & 2148 & $<3$ & 10 & 5 May 2010-present & wire dia $=0.254 \mathrm{~mm}$, unaspirated \\
\hline Scientific & $\mathrm{CU}^{\mathrm{CSAT}}{ }^{\mathrm{c}}$, ver 3 & 0536 & 2150 & 0 & 10 & 14 Jan 2008-21 Feb 2008 & F-CAL: 6 Nov 2007 (on loan from EOL) \\
\hline CSAT3 Three & $\mathrm{CU} \mathrm{CSAT}^{\mathrm{c}}$, ver3 & 0438 & 2150 & 0 & 10 & 21 Feb $2008-31$ Oct 2008 & F-CAL: Feb 2008 \\
\hline Dimensional & CU CSAT ${ }^{\mathrm{c}}$, ver 4 & 0328 & 2150 & 0 & 10 & 31 Oct $2008-28$ Sep 2010 & F-CAL: Oct 2008 \\
\hline \multirow{4}{*}{$\begin{array}{l}\text { Sonic ane- } \\
\text { mometer }\end{array}$} & $\mathrm{CU}_{\mathrm{CSAT}}^{\mathrm{c}}$, ver4 & 0198 & 2150 & 0 & 10 & 28 Sep 2010-present & F-CAL: Sep 2010 \\
\hline & EOL CSAT, ver3 & 0674 & 2150 & $\approx 160$ & 10 & 27 Sep 2009-17 Jan 2010 & F-CAL: 17 Nov 2008 (ver3) \\
\hline & EOL CSAT, ver4 & 0674 & 2150 & $\approx 160$ & 10 & 17 Jan $2010-21$ Oct 2011 & $\begin{array}{l}\text { F-CAL: } 6 \text { Jan } 2005 \text { (ver4) } \\
\text { on } 17 \text { Jan } 2010 \text {, changed from ver3 to ver } 4\end{array}$ \\
\hline & EOL CSAT, ver3 (OLD) & 0674 & 2150 & $\approx 160$ & 10 & 21 Oct 2011-27 Jul 2012 & $\begin{array}{l}\text { F-CAL: } 4 \text { Aug } 2006 \text { (ver3) } \\
\text { on } 21 \text { Oct } 2011 \text {, changed from ver4 to ver3 }\end{array}$ \\
\hline
\end{tabular}

${ }^{a}$ Horizontal distance from the University of Colorado (CU) CSAT sensor. ${ }^{\mathrm{b}}$ Number of samples per second (Hz). ${ }^{\mathrm{c}}$ The $2150 \mathrm{~cm}$ CU CSAT is used to determine the horizontal wind speed $(U) .{ }^{\mathrm{d}}$ The CSAT sonic temperature $\left(T_{\mathrm{S}}\right)$ corrected for humidity is $T_{\mathrm{S}}^{\text {air }}=T_{\mathrm{S}}(1+0.51 q)^{-1}$ where $q$ is specific humidity. The designation "ver3" and "ver4" represent CSAT embedded code firmware versions 3 and 4, respectively. The CU and EOL CSATs are both mounted on booms that are oriented at $203^{\circ}$ from true north (e.g., pointed toward the southwest).

data were rarely flagged, however, for higher winds, around $2-4 \%$ of the samples were flagged. The number of spikes was also affected by the relative humidity. Further details of the despiking can be found in the on-line discussion of Burns et al. (2012). Any CSAT data sample deemed questionable by the CSAT diagnostic flag was replaced with a linear fit between valid samples.

Here, we briefly summarize the sequence of events that led to our study (also see Table 1). In 2008, the three University of Colorado (CU) CSATs (all ver3) were sent to Campbell Scientific, Inc. for recalibration and one of them (serial number 0328) was upgraded to ver4. After deploying CU CSAT 0328 at $21.5 \mathrm{~m}$, we observed nighttime $H_{\text {CSAT val- }}$ ues that were frequently above zero, suggesting heat was being transported from the surface to the atmosphere. Though such conditions are possible for short periods (e.g., due to warm air advection), we have rarely observed such phenomena in the previous $10 \mathrm{yr}$ of measurements. These anomalous $H_{\mathrm{CSAT}}$ measurements were strongly correlated with high winds (Fig. 1).

Because we were suspicious about these above-zero nighttime $H_{\mathrm{CSAT}}$ values, we deployed CSAT 0674 from the National Center for Atmospheric Research (NCAR) Earth Observing Laboratory (EOL) at the same level and orientation as the CU CSAT. The EOL CSAT 0674 initially used ver3, which we changed to ver4 partway through our study (Table 1). To change from ver3 to ver4, the processing chip in the CSAT electronics enclosure and the firmware versionspecific calibration coefficients were both changed, but the sonic head was not disturbed.

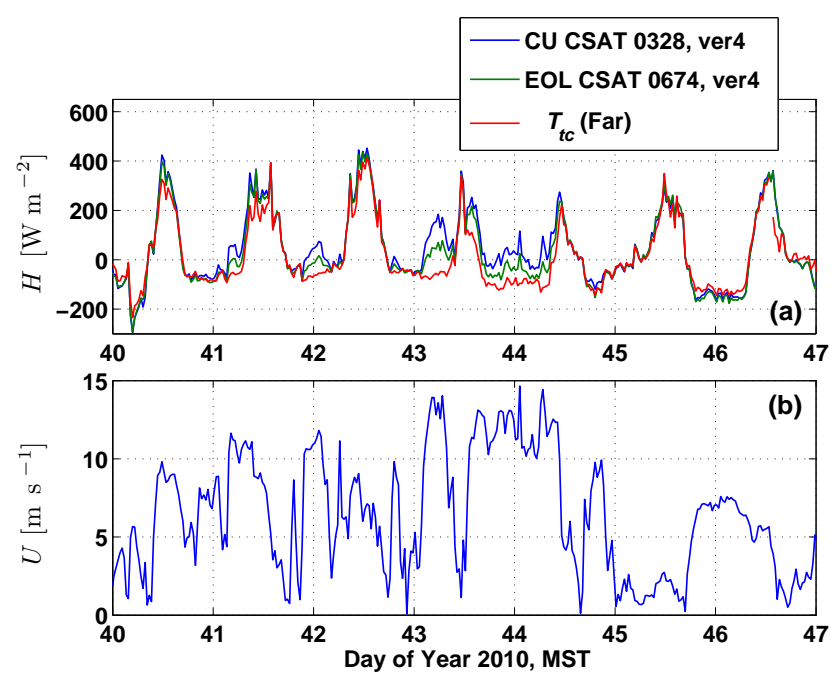

Fig. 1. Time series of $21.5 \mathrm{~m}$ (a) sensible heat flux $H$ and (b) horizontal wind speed $U . H$ is calculated using temperature from either a sonic anemometer or the far thermocouple $T_{\mathrm{tc}}$ as specified in the legend (see Table 1 for details). The thermocouple uses the $\mathrm{CU}$ CSAT vertical wind to determine $H$.

Additional air temperature information was provided near the $21.5 \mathrm{~m}$ level by a $0.254 \mathrm{~mm}$ E-type thermocouple that was located about $1.4 \mathrm{~m}$ from the CU CSAT and sampled at $1 \mathrm{~Hz}$. The thermocouple temperature fluctuations $\left(T_{\mathrm{tc}}^{\prime}\right)$ are correlated with $w^{\prime}$ from the CU CSAT to calculate a sensible heat flux (e.g., $H_{T_{\mathrm{tc}}}=\bar{\rho} \overline{c_{\mathrm{p}}} \overline{w^{\prime} T_{\mathrm{tc}}^{\prime}}$ ). Because we were concerned about flux loss due to horizontal separation and lack of highfrequency sampling, an identical E-type thermocouple was 
deployed in May 2010 within $3 \mathrm{~cm}$ of the CU CSAT transducers and sampled at $10 \mathrm{~Hz}$. These two thermocouples and their associated heat fluxes will be distinguished from each other using the terms "Near" and "Far" as shown in Table 1 . The thermocouples used in our study were created by spot-welding the $0.254 \mathrm{~mm}$ chromel and constantan wires together and leaving the clipped ends intact to improve the thermal frequency-response (Fuehrer et al., 1994). The other temperature sensor at the $21.5 \mathrm{~m}$ level was a mechanically aspirated, slow-response temperature-humidity sensor (Vaisala HMP35-D probe) which we use as a reference sensor for time-averaged comparisons.

\section{Results and discussion}

\subsection{Comparison of sensible heat fluxes}

If sensible heat flux is calculated using sonic temperature from two different CSATs and temperature from a co-located thermocouple, there are large $H$ differences during periods of strong winds that are most obvious at night (Fig. 1). In a perfect sonic anemometer, the path-length $d$ is constant; however, real world changes to $d$ can occur as the sensor material expands and contracts due to temperature changes or wind-induced stresses or vibrations (Smedman et al., 2007). Lanzinger and Langmack (2005) use a Thies twodimensional sonic anemometer to show that a $50 \mathrm{~K}$ temperature change results in a $0.4 \mathrm{~mm}$ change in $d$, which produces a $1.2 \mathrm{~K}$ error in $T_{\mathrm{s}}$. We did not observe any temperaturedependent heat flux differences in our study.

After separating the heat flux data by day and night, there is a consistent trend in the $H_{\mathrm{CSAT}}-H_{T_{\mathrm{tc}}}$ difference; for $U>\approx 8 \mathrm{~m} \mathrm{~s}^{-1}, H_{\mathrm{CSAT}}-H_{T_{\mathrm{tc}}}>0$ and the difference increases as wind speed increases up to a difference of $\approx 250 \mathrm{~W} \mathrm{~m}^{-2}$ at $U \approx 17 \mathrm{~m} \mathrm{~s}^{-1}$ (Fig. 2). Our original observation that this was primarily a nighttime problem is incorrect, because the daytime and nighttime differences are qualitatively similar. We have separated the panels of Fig. 2 into periods when different configurations of CSATs were on the tower (Table 1). By comparing Fig. 2a and b, we find that $H_{\text {CSAT }}$ EOL ver3 agreed better with $H_{T_{\text {tc }}}$ than $H_{\text {CSAT }}$ EOL ver4. Also, $H_{\mathrm{CSAT}}-H_{T_{\mathrm{tc}}}$ for EOL CSAT ver3 did not have as strong a dependence on wind speed as ver4.

One issue of concern with the far thermocouple is the $\approx 1.4 \mathrm{~m}$ horizontal sensor separation from the CU CSAT (Horst and Lenschow, 2009). For $H_{\mathrm{CSAT}}-H_{T_{\mathrm{tc}}}$ using either the far (Fig. 2c) or near (Fig. 2d) thermocouple, a very similar pattern of increasing $H$ difference with increasing wind speed is observed, implying that $H_{T_{\mathrm{tc}}}\left(\right.$ Far) $\approx H_{T_{\mathrm{tc}}}$ (Near). This encourages us to believe that using the far thermocouple results in a viable heat flux. As one would expect, there is less scatter in $H_{\mathrm{CSAT}}-H_{T_{\mathrm{tc}}}$ using the near thermocouple. The effect of sensor separation on $H_{T_{\mathrm{tc}}}$ (Far) and frequency response of the thermocouples are revisited in Sect. 3.2.
In order to make a connection to the results from Turnipseed et al. (2002), we examined heat flux data collected within the period of 1998 to 2007. We found that $H_{\mathrm{CSAT}}-H_{T_{\mathrm{tc}}}$ (Far) using CSAT 0226 ver 3 in 2007 has a similar wind speed-dependence to that observed with the other CSATs (Fig. 2e). CSAT 0226 was initially deployed in 1998 (Table 1) which is relevant to our consideration of the surface energy balance in Sect. 3.6.

Although the focus here has been on the vertical heat flux, there are also differences in the horizontal heat flux (results not shown). We found that the $\bar{\rho} \overline{c_{\mathrm{p}}}\left(\overline{u^{\prime} T_{\mathrm{s}}^{\prime}}-\overline{u^{\prime} T_{\mathrm{tc}}^{\prime}}\right)$ difference is larger in magnitude and of opposite sign than the $H_{\mathrm{CSAT}}-H_{T_{\mathrm{tc}}}$ difference (i.e., $\overline{u^{\prime} T_{\mathrm{s}}^{\prime}}<\overline{u^{\prime} T_{\mathrm{tc}}^{\prime}}$ whereas $\left.\overline{w^{\prime} T_{\mathrm{s}}^{\prime}}>\overline{w^{\prime} T_{\mathrm{tc}}^{\prime}}\right)$. We will provide further explanation for these differences in Sect. 3.5.

The heat flux differences we have presented here are qualitatively different from previous results using a Gill Solent sonic anemometer mentioned in the introduction (e.g., Grelle and Lindroth, 1996; Aubinet et al., 2000; Smedman et al., 2007). We found $H_{\mathrm{CSAT}}$ tended to be larger than $H_{T_{\mathrm{tc}}}$ as wind speed increased for all conditions, whereas the Solent heat flux tended to be larger in magnitude than $H$ from the PRT. Therefore, in weakly stable conditions, we find $H_{\mathrm{CSAT}}>H_{T_{\mathrm{tc}}}$ while the previous studies with the Gill sonic anemometer found $H_{\text {Solent }}<H_{\text {PRT }}$. In weakly unstable conditions, $H_{\mathrm{CSAT}}>H_{T_{\mathrm{tc}}}$ and $H_{\text {Solent }}>H_{\mathrm{PRT}}$. We would not necessarily expect the two sonic anemometers to behave similarly (because the CSAT and Solent have very different geometries, firmware, etc.), but it is worthwhile to note that the heat flux errors are in the opposite direction for weakly stable conditions, suggesting different reasons for the error.

\subsection{Spectral comparisons}

To gain further insight into the $H_{\mathrm{CSAT}}-H_{T_{\mathrm{tc}}}$ differences, we examine the spectra of $w^{\prime}, T_{\mathrm{s}}^{\prime}$, and $T_{\mathrm{tc}}^{\prime}$ and their associated cospectra and ogives (Friehe et al., 1991) for high-wind conditions (Fig. 3). The vertical wind and sonic temperature spectra from the two CSATs are in good agreement, but show the effect of high-frequency noise and aliasing. For $f>1 \mathrm{~Hz}$, the $f S_{T_{\mathrm{s}}}$ noise appears to follow the $f^{+1}$ slope that is typical of white noise, and indicative of the true temperature signal dropping below the sensor noise threshold (Kaimal and Gaynor, 1991; Kaimal and Finnigan, 1994). Low-pass filtering $T_{\mathrm{S}}$ to remove this noise did not significantly change $H_{\text {CSAT }}$ (Burns et al., 2012). The temperature spectra from the thermocouples are attenuated at frequencies above $\approx 1 \mathrm{~Hz}$, because the thermal mass of the thermocouple wire limits the response time. In high-wind conditions (i.e., when the $f S_{w}$ and $f S_{T}$ energy peak is shifted to higher frequencies), we observe that $H_{T_{\mathrm{tc}}}$ (Far) is about $10 \%$ smaller than $H_{T_{\mathrm{tc}}}$ (Near), presumably due to the spatial separation between the far thermocouple and the CU CSAT. The $1-\mathrm{Hz}$ sampling rate does not significantly diminish the magnitude of the flux (e.g., Lenschow et al., 1994), which is confirmed by the 

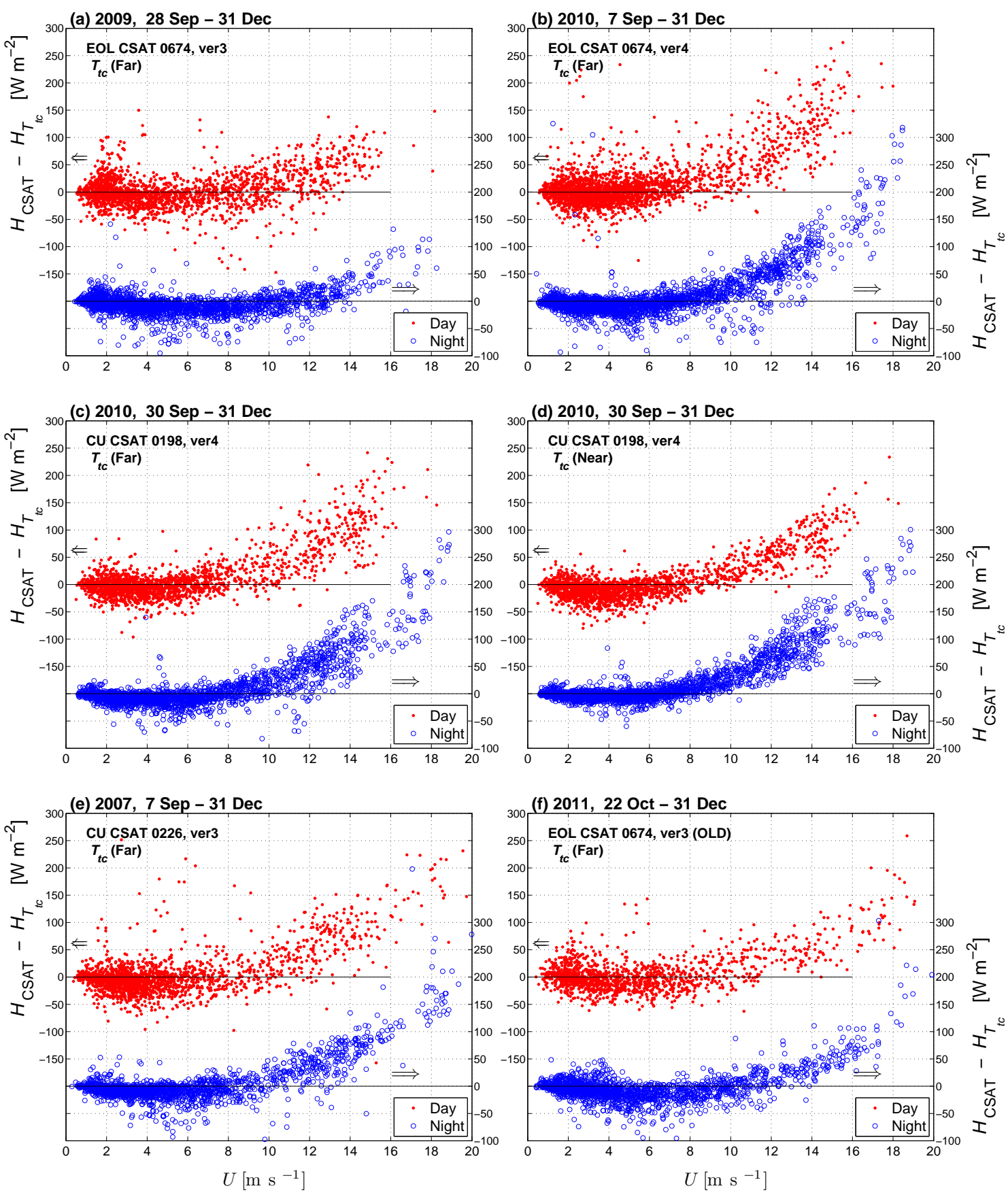

Fig. 2. The sensible heat flux difference calculated with the CSAT and thermocouple $\left(H_{\mathrm{CSAT}}-H_{T_{\mathrm{tc}}}\right)$ versus the $21.5 \mathrm{~m}$ horizontal wind speed $U$. In (a)-(f), the time period and the particular CSAT and thermocouple used to determine the sensible heat fluxes are shown in the upper left corner (see Table 1 for sensor details). Each point represents $H$ calculated over 30 min, then separated into daytime (left-side axis) and nighttime (right-side axis) periods as shown by the horizontal arrows and legend. EOL CSAT 0674 ver3 is used in both (a) and (f), but an older set of factory-calibration coefficients is used in (f).

excellent agreement between the $10-\mathrm{Hz}$ and $1-\mathrm{Hz} \mathrm{Co}_{w} T_{\mathrm{tc}}$ and $H$ ogive calculations using the near thermocouple (Fig. 3b).

During the day, the low-frequency parts of $f S_{T}$ and $f \mathrm{Co}_{w T}$ for the CSATs and thermocouple are in fairly good agreement (Fig. 3a). At night, however, $f S_{T_{\mathrm{tc}}}$ has more low-frequency variance than the CSATs, and $f \mathrm{Co}_{w T_{\mathrm{tc}}}$ differs dramatically from the cospectra of the two CSATs. The $H$ ogive reveals nocturnal $H_{T_{\mathrm{tc}}} \approx-100 \mathrm{~W} \mathrm{~m}^{-2}$ compared to $H_{\mathrm{CSAT}} \approx-30 \mathrm{~W} \mathrm{~m}^{-2}$ (Fig. $3 \mathrm{~b}$ ). For smaller wind speeds, the spectra and cospectra come into better agreement (Fig. 4). 
(a) For $U>10 \mathrm{~m} \mathrm{~s}^{-1}$ (Day)

Year $=2010$ Month $=11$

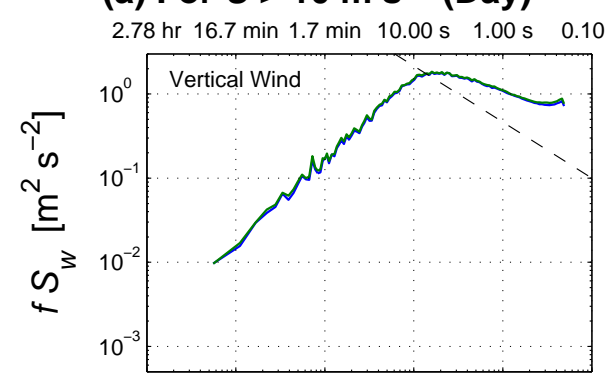

No. $30-$ min Periods : 80 out of 1438
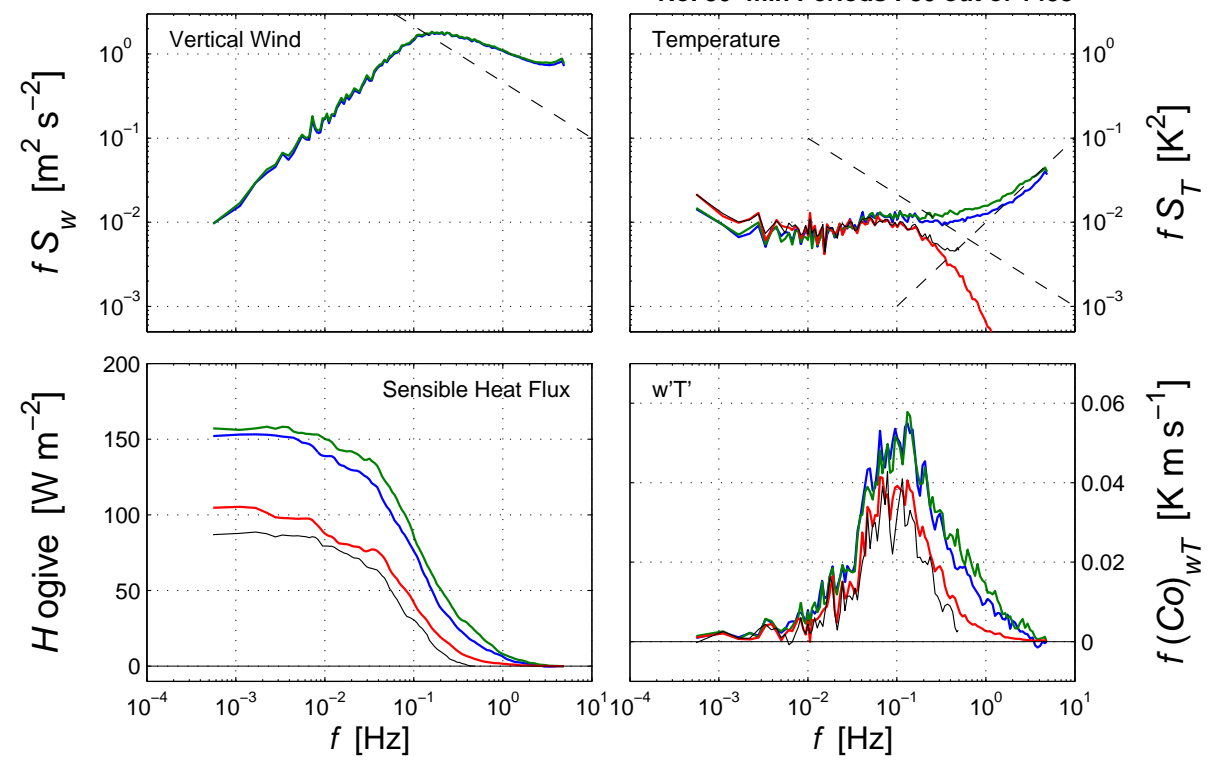

(b) For $U>10 \mathrm{~m} \mathrm{~s}^{-1}$ (Night)

Year $=2010$ Month $=11$

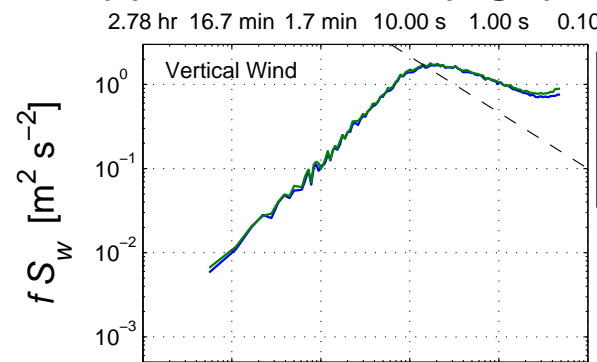

s No. $30-m i n$ Periods : 157 out of 1438
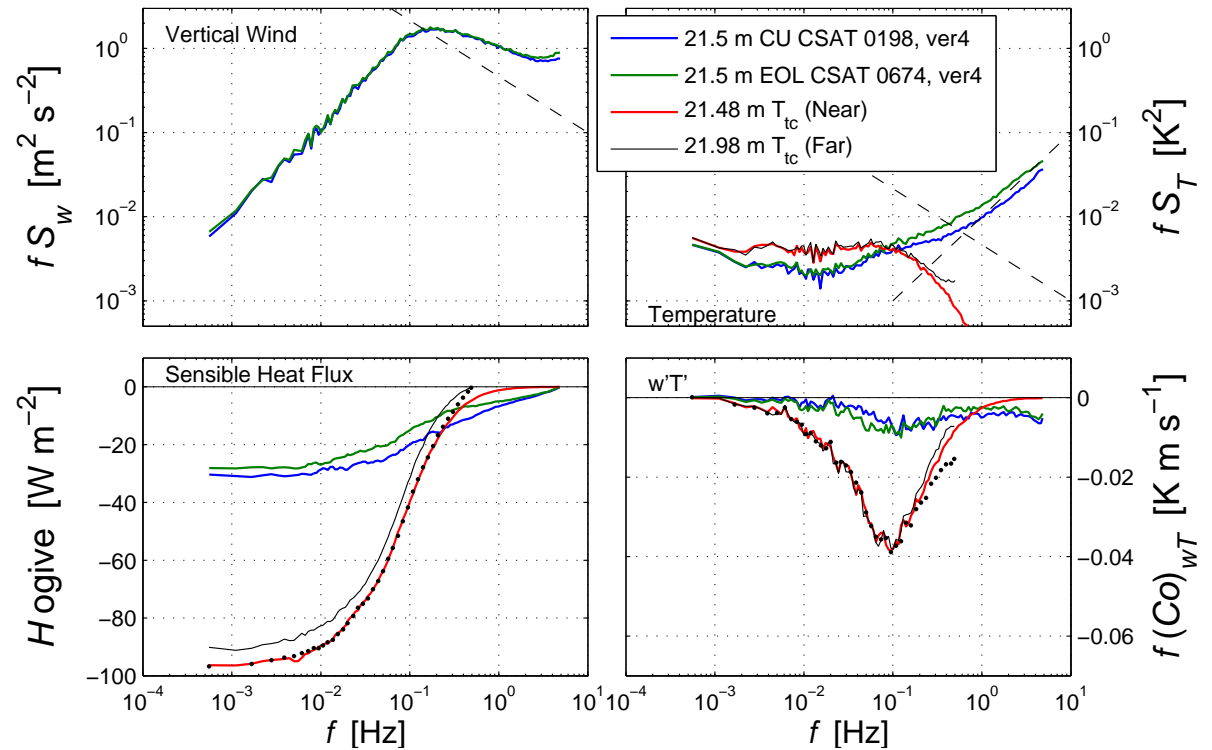

Fig. 3. Mean (a) daytime and (b) nighttime values of vertical wind spectra $S_{w}$, temperature (either $T_{\mathrm{S}}$ or $T_{\mathrm{tc}}$; see legend and Table 1) spectra $S_{T}, \overline{w^{\prime} T^{\prime}}$ cospectra $\mathrm{Co}_{w T}$, and sensible heat flux $H$ ogive versus frequency $f$. These are 30-min periods from November, 2010 selected for wind speed $U$ greater than $10 \mathrm{~m} \mathrm{~s}^{-1}$ (the number of 30-min periods that match this criterion is listed above the $S_{T}$ panel). Co-spectral analysis between the $1-\mathrm{Hz}$ far thermocouple and $10-\mathrm{Hz} w$ uses $w$ that has been down-sampled to $1 \mathrm{~Hz}$ by picking samples that are closest to the $1-\mathrm{Hz}$ samples in time. Similarly, the $10-\mathrm{Hz}$ near thermocouple data resampled to $1 \mathrm{~Hz}$ are shown by the black dots in the $\mathrm{Co}_{w T}$ and $H$ ogive panels of (b). The dashed lines show a $f^{-2 / 3}$ and $f^{+1}$ slope. Note that the $S_{w}$ lines from the two CSATs are nearly indistinguishable from each other. 

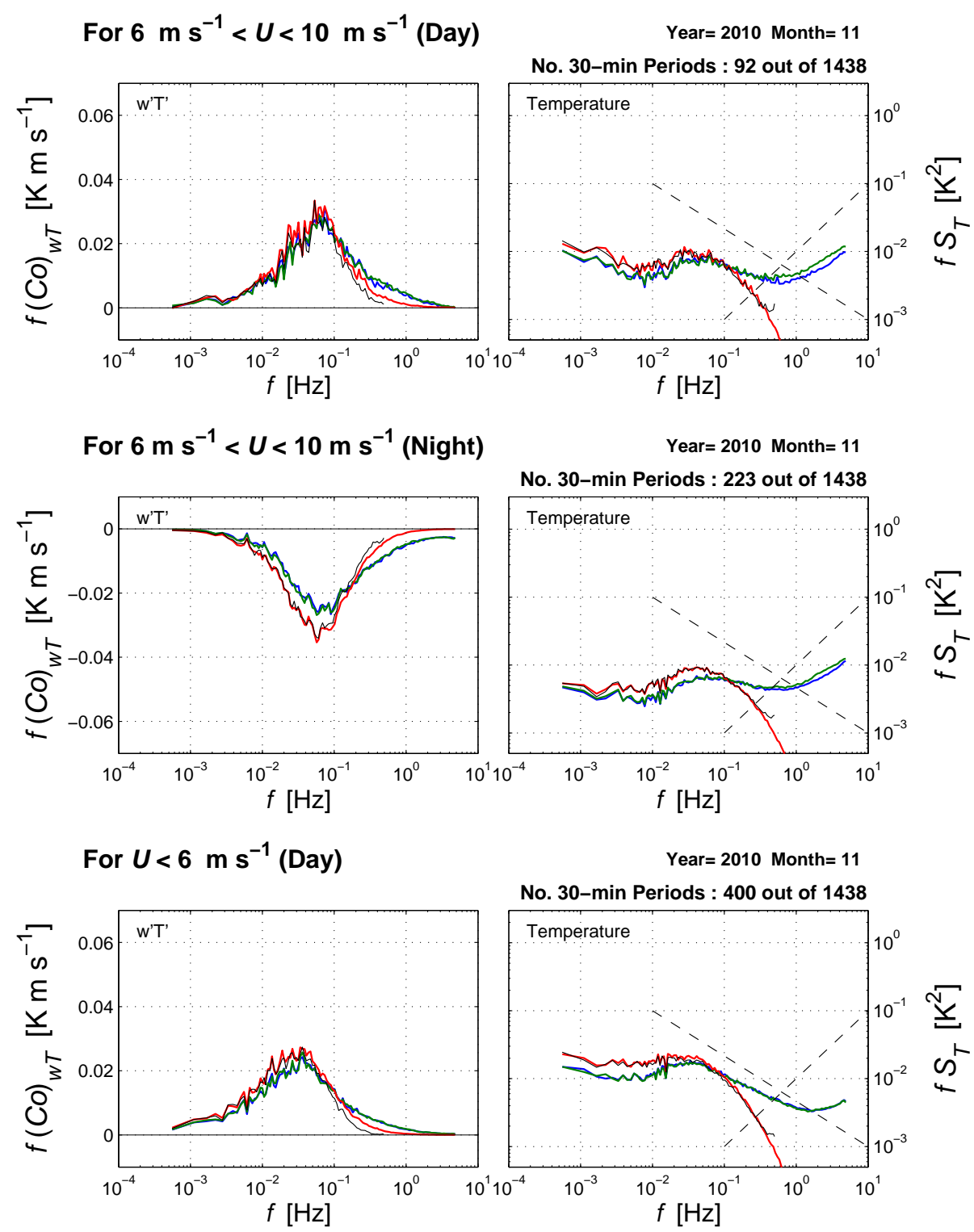

For $U<6 \mathrm{~m} \mathrm{~s}^{-1}$ (Night)
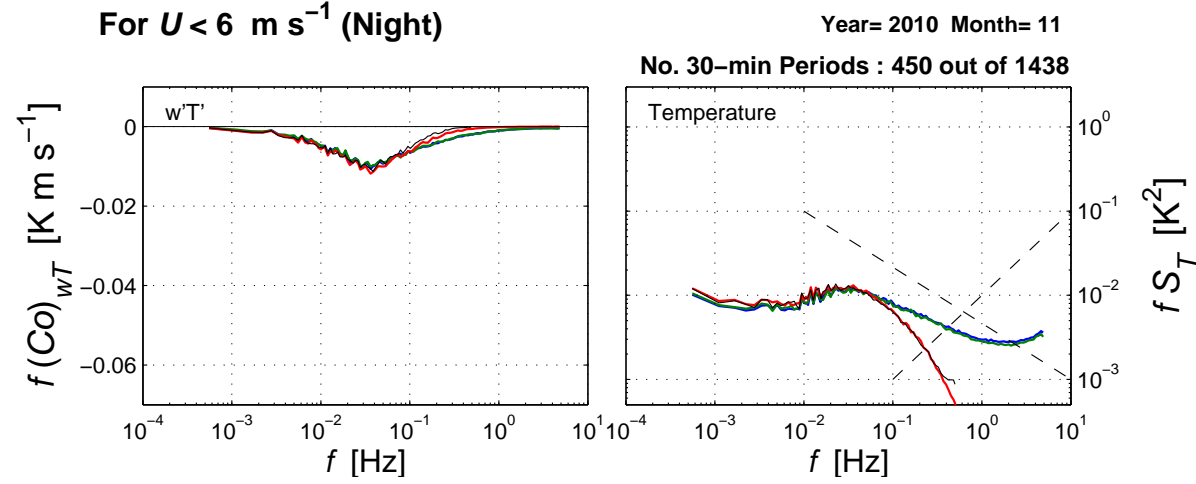

Fig. 4. The (left column) $\overline{w^{\prime} T^{\prime}}$ cospectra $(\mathrm{Co})_{w T}$ and (right column) temperature spectra $S_{T}$ for medium- and low-wind conditions (see Fig. 3 for the legend and further details). 

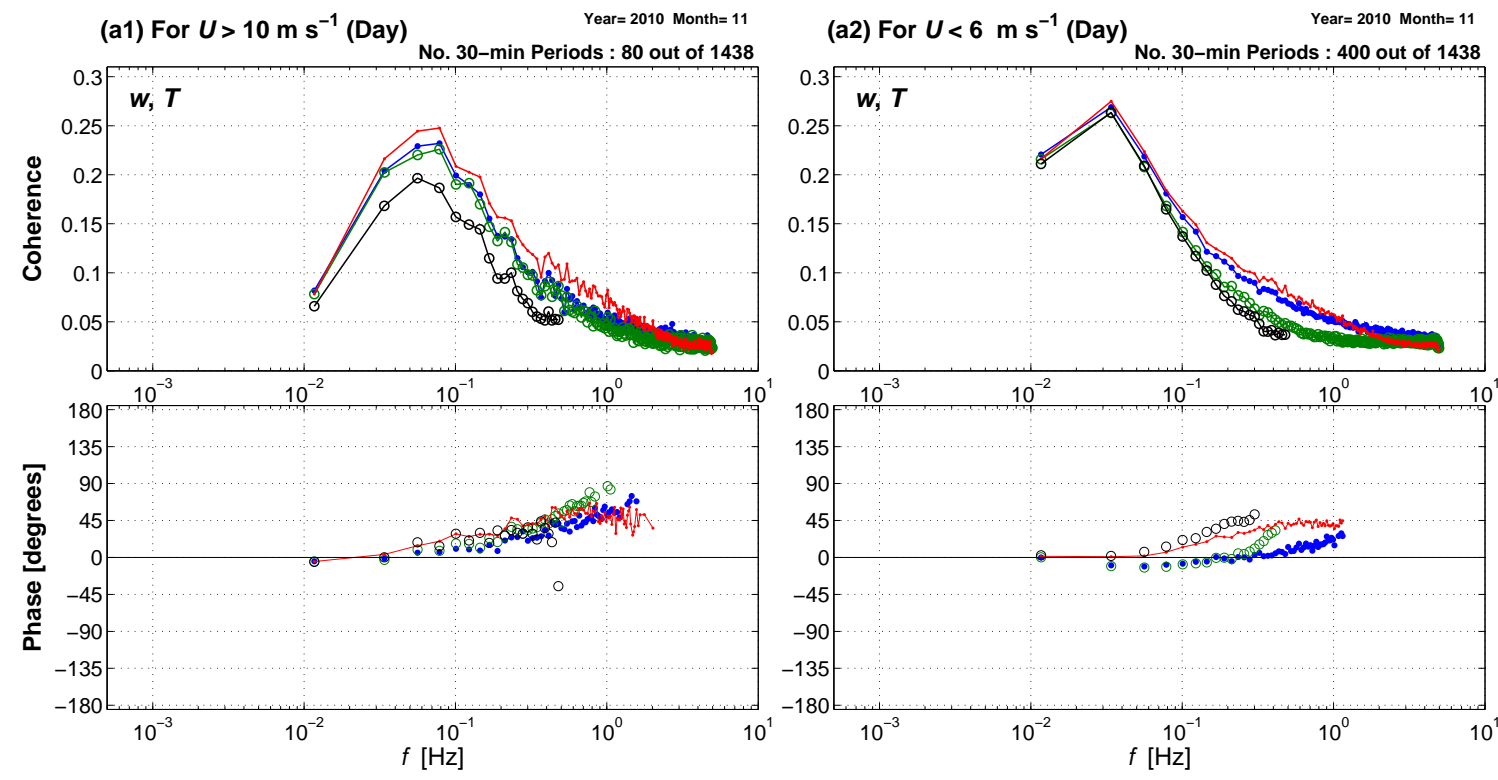

(b1) For $U>10 \mathrm{~m} \mathrm{~s}^{-1}$ (Night)

Year= 2010 Month $=11$

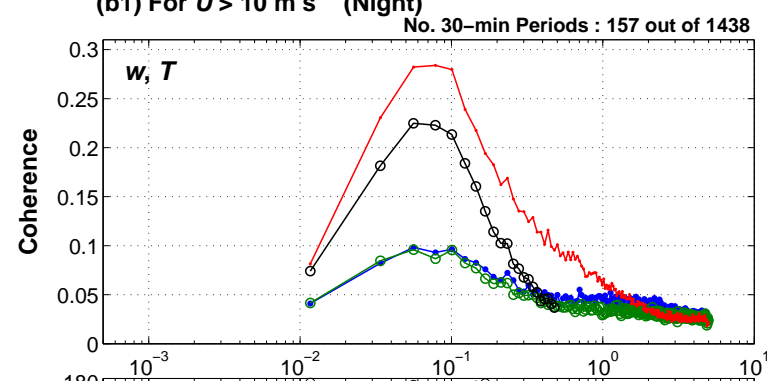

(b2) For $U<6 \mathrm{~m} \mathrm{~s}^{-1}$ (Night)

Year 2010 Month $=11$
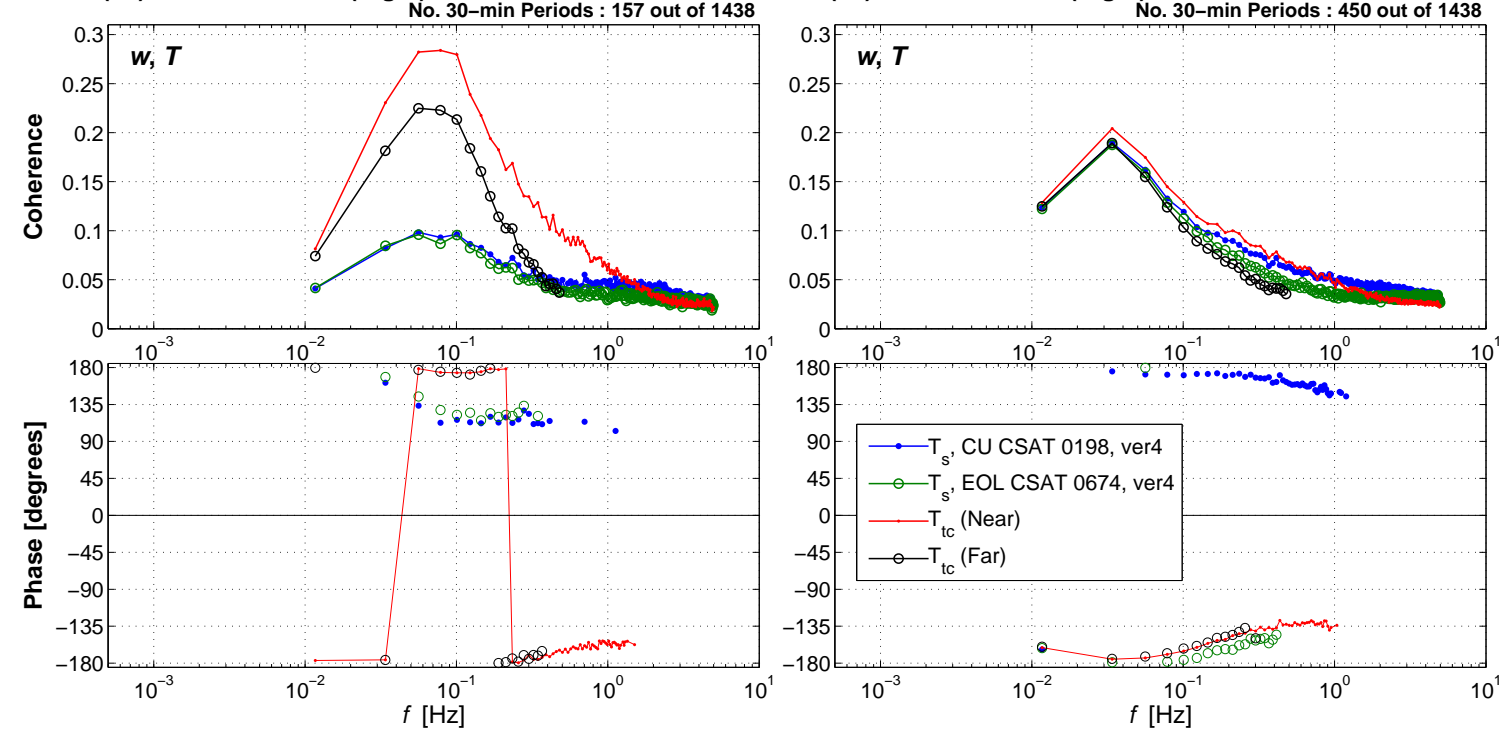

Fig. 5. The spectral coherence (Coh) and phase between the CU CSAT 0198 ver4 vertical wind $w$ and temperature $T$ from different sensors (as described in the legend) versus frequency $f$. Data are from November 2010 for (a1) day high-winds, (a2) day low-winds, (b1) night high-winds, and (b2) night low-winds where each line represents the average from all 30-min periods that satisfy the criteria listed above the Coh panel. To calculate these statistics, 224 equi-sized $(N=40$ pts $)$ linear frequency bins were used. The phase is not shown for Coh $<0.05$. For clarity, solid lines are not shown for all $w, T$ combinations in the phase panels.

The spectral coherence (Coh) and phase differences between the CU CSAT ver4 vertical wind and various temperature sensors provide further insight into the issues with $T_{\mathrm{S}}$. The $w, T$ coherence reaches a maximum between 0.2 and 0.3 for most conditions and all $w, T$ combinations, except for high winds at night where $\mathrm{Coh}_{w T_{\mathrm{s}}}$ only reaches a maximum of 0.1 (Fig. 5b1). Note that this drop in coherence is true with $T_{\mathrm{S}}$ from both the CU and EOL CSATs and is indicative of the decorrelation between $w^{\prime}$ and $T_{\mathrm{s}}^{\prime}$ that occurs at night with high winds. This result emphasizes how challenged the
CSAT is to measure temperature fluctuations at night with high winds (i.e., when the true temperature variance is small). Note that the peak of $f S_{T_{\mathrm{tc}}}$ in nighttime windy conditions is smaller than $10^{-2} \mathrm{~K}^{2}$ (Fig. 3b), whereas in all other conditions the peak in $f S_{T_{\mathrm{tc}}}$ is at or above $10^{-2} \mathrm{~K}^{2}$ (Figs. 3a and 4).

The phase between $w^{\prime}$ and $T^{\prime}$ for turbulent time scales ( $f>\approx 0.01 \mathrm{~Hz}$ ) should be $180^{\circ}$ at night and $0^{\circ}$ during the day (e.g., Stull, 1988). We find the $w, T$ phase generally follows this pattern (Fig. 5), except during high winds at night 

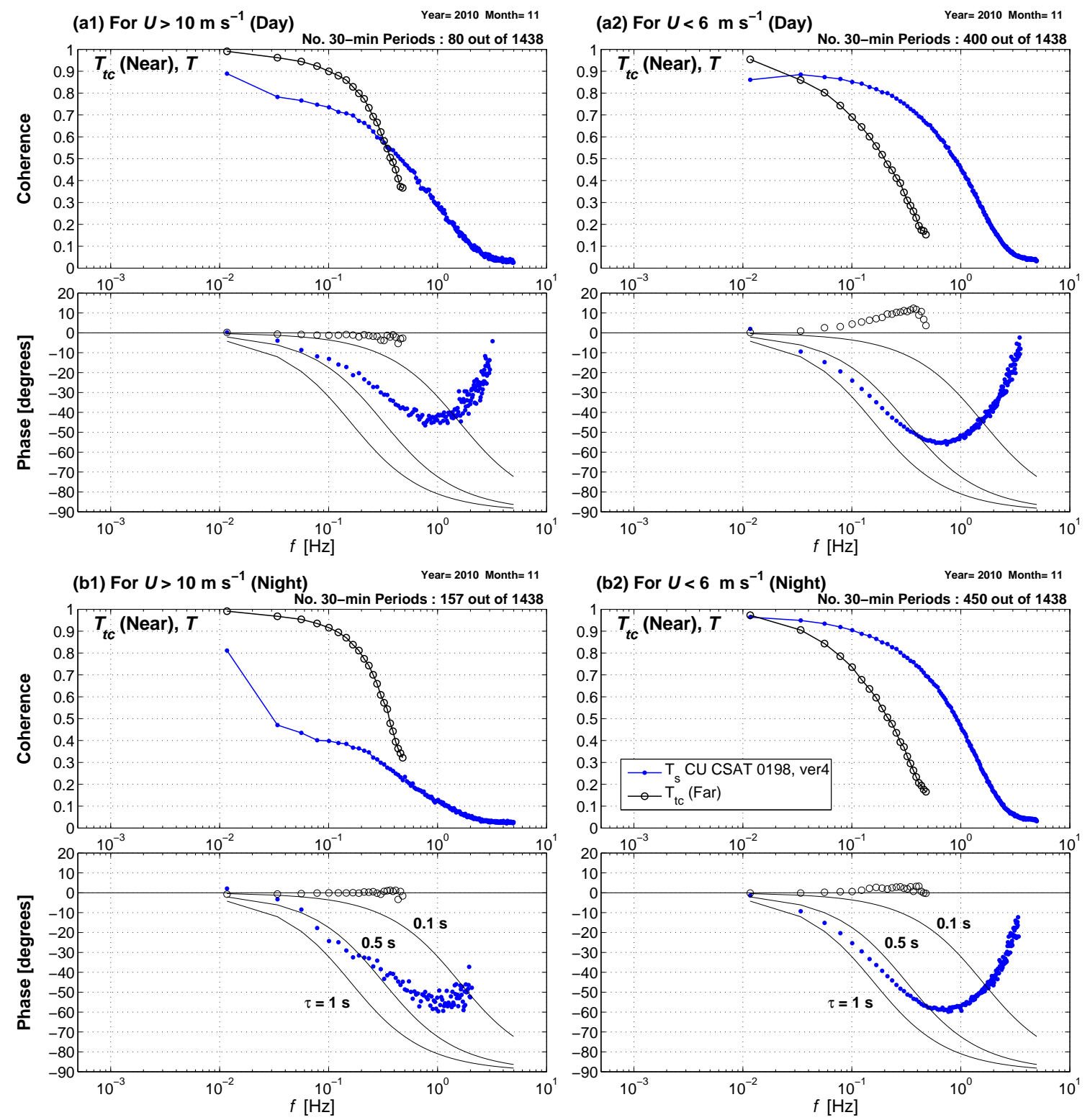

Fig. 6. As in Fig. 5, except comparing temperature from the near thermocouple $\left(T_{\mathrm{tc}}\right.$, Near) to the far thermocouple $\left(T_{\mathrm{tc}}\right.$, Far $)$ and sonic $\left(T_{\mathrm{S}}\right)$ temperatures as specified in the legend. The solid lines in the phase panels are the phase angles from a first-order linear differential equation with time constants of $\tau=1 \mathrm{~s}, 0.5 \mathrm{~s}$, and $0.1 \mathrm{~s}$. To calculate the near and far thermocouple statistics, the near thermocouple 10-Hz samples are down-sampled to $1 \mathrm{~Hz}$ by picking the $10-\mathrm{Hz}$ samples closest to the $1-\mathrm{Hz}$ samples in time.

where there is an apparent shift in the $w, T_{\mathrm{S}}$ phase angle toward $90^{\circ}$ (Fig. 5b1). Lenschow and Sun (2007) show that $w^{\prime}$ should lag $u^{\prime}$ by a phase angle of around $90^{\circ}$ which suggests that $T_{\mathrm{s}}^{\prime}$ in Fig. $5 \mathrm{~b} 1$ is being affected (or contaminated) by streamwise velocity fluctuations.

We also used coherence/phase analysis to evaluate potential measurement issues due to the thermal time response of the thermocouple (Fig. 6). For high-wind conditions, the $T_{\mathrm{tc}}^{\mathrm{Near}}, T_{\mathrm{tc}}^{\mathrm{Far}}$ coherence for $f<0.2 \mathrm{~Hz}$ is larger than 0.8 and greater than that of $T_{\mathrm{tc}}^{\mathrm{Near}}, T_{\mathrm{S}}$ (Fig. 6a1 and b1). In contrast, for low winds, the $T_{\mathrm{tc}}^{\mathrm{Near}}, T_{\mathrm{S}}$ coherence is generally greater than the coherence between the two thermocouples due to the thermocouple spatial separation (Fig. $6 \mathrm{a} 2$ and b2). Previously published results show that co-located, fast-response temperature sensors should have a coherence of 0.95 or higher up to $f \approx 2 \mathrm{~Hz}$ (e.g., Verma et al., 1979; Friehe and Khelif, 1992). For our thermocouple, the $T_{\mathrm{tc}}^{\mathrm{Near}}, T_{\mathrm{s}}$ coherence is above 0.9 only for $f<\approx 0.1 \mathrm{~Hz}$ indicating that higherfrequencies are being attenuated. However, a visual comparison of $\overline{w^{\prime} T_{\text {tc }}^{\prime}}$ cospectra (Fig. 3b) with previously published cospectra (e.g., Kaimal and Finnigan, 1994; Blanken et al., 
1998; Massman and Clement, 2005) suggests that heat fluxes calculated using the near thermocouple are reasonable.

Even though the two thermocouples are spatially separated, the phase between them is close to zero because both sensors have the same response-time characteristics (Fig. 6). In contrast, the $T_{\mathrm{tc}}^{\mathrm{Near}}, T_{\mathrm{s}}$ phase angle is negative because the thermocouple responds more slowly to temperature changes than the CSAT. We can use the phase angle to estimate that the thermocouple response-time is around $0.4 \mathrm{~s}$ in high winds (Fig. 6a1 and b1) and $0.7 \mathrm{~s}$ in low winds (Fig. 6a2 and b2). The phase is sensitive to the attenuation of the true temperature signal by the thermocouple which explains why the phase angle curves upward at around $0.8 \mathrm{~Hz}$ in Fig. 6.

Temperature sensor response is typically characterized by a first-order linear differential equation (Benedict, 1977), where the phase angle will depend on the thermal time constant and should approach $-90^{\circ}$ at higher frequencies (Fig. 6). The thermocouple response-time can be roughly estimated as the time constant $\tau=\rho_{\mathrm{tc}} c V /(h A)$ in a first-order system, where $\rho_{\text {tc }}$ is the density of chromel $\left(8500 \mathrm{~kg} \mathrm{~m}^{-3}\right)$, $c$ is chromel heat capacity $\left(456 \mathrm{~J} \mathrm{~kg}^{-1} \mathrm{~K}^{-1}\right), V$ is the weld volume $\left(\mathrm{m}^{3}\right), A$ is the weld surface area $\left(\mathrm{m}^{2}\right)$, and $h$ is the convective heat transfer coefficient $\left(\mathrm{W} \mathrm{m}^{-2} \mathrm{~K}^{-1}\right)$. Because the properties of chromel and constantan are similar, we only used chromel properties. If we follow the methodology outlined by Friehe and Khelif (1992) and assume the weld is approximately spherical in shape (with a diameter twice the wire diameter), then the time constant of our thermocouple is $\tau \approx 0.24 \mathrm{~s}$ for an air velocity of $15 \mathrm{~m} \mathrm{~s}^{-1}$ and $\tau \approx 1.6 \mathrm{~s}$ for still air. These results are not too different from the responsetimes estimated from Fig. 6 and consistent with published results for thermocouples (Farahmand and Kaufman, 2001). All estimations of the thermocouple response time indicate that it is significantly slower than the $0.1 \mathrm{~s}$ still air time constant of the PRT used by Grelle and Burba (2007). Although one advantage of the thermocouple used in our study is that it will not break during high-wind and precipitation events, using an alternate temperature sensor with a faster responsetime would allow confirmation that there is not any flux loss in $H_{T_{\mathrm{tc}}}$.

We considered the possibility of tower/sonic vibration or movement affecting the transit times (e.g., $t_{1}$ and $t_{2}$ in Eq. 3) and causing the $\overline{w^{\prime} T_{\mathrm{s}}^{\prime}}$ error. However, the main source of the problem appears to be with $T_{\mathrm{s}}^{\prime}$ not $w^{\prime}$ because $\overline{w^{\prime} T_{\mathrm{tc}}^{\prime}}$, which uses the same CSAT $w^{\prime}$, produces reasonable heat fluxes (e.g., predominantly negative at night). Also, similar highfrequency noise in CSAT $S_{T}$ (not shown here) has been observed on a 30-m tower during high winds in the CHATS field project (Patton et al., 2011). This suggests the problem is not specific to the NWT tower. Without an independent measure of $w^{\prime}$, it is difficult to check the vertical wind, but we note that $f S_{w}$ in high winds is flatter than the expected $-2 / 3$ slope (Fig. 3). Finally, we also considered the $\overline{w^{\prime} q^{\prime}}$ term

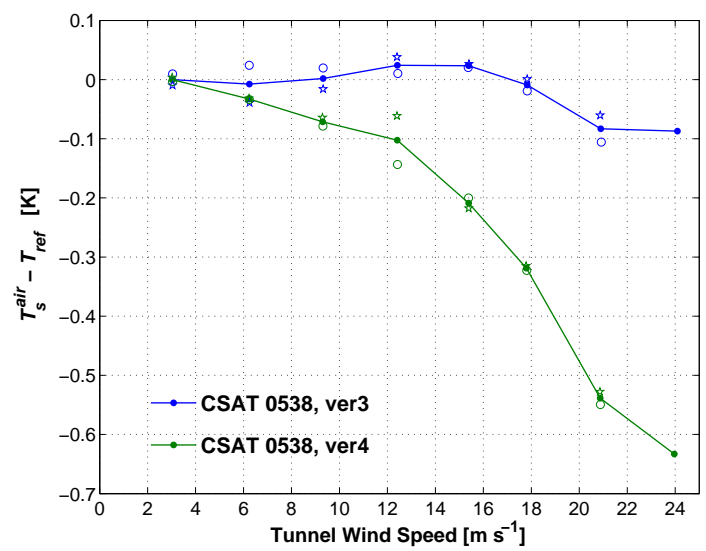

Fig. 7. The mean temperature difference $\left(T_{\mathrm{S}}^{\mathrm{air}}-T_{\text {ref }}\right)$ versus wind tunnel pitot tube wind speed. The CSAT 0538 air temperature $\left(T_{\mathrm{S}}^{\text {air }}\right)$ is calculated following Eq. (4) and uses either embedded code ver3 or ver4 (see legend). $T_{\text {ref }}$ is from a mechanically aspirated T/RH sensor (Sensirion, model SHT 75) located near the CSAT transducer. Mean values were calculated over $20 \mathrm{~min}$ at each tunnel wind speed. The temperature difference has been shifted so that the value at the lowest tunnel speed equals zero. Data were collected as tunnel wind speed was increasing (stars) as well as decreasing (open circles), and the solid line is the mean value at each wind speed. The Campbell Scientific factory calibrations of CSAT 0538 were performed on 29 March 2012 for ver3 and 30 April 2010 for ver4.

in Eq. (5) but found it too small to explain the discrepancy between $H_{\mathrm{CSAT}}$ and $H_{T_{\mathrm{tc}}}$ (results not shown).

\subsection{Mean temperature differences versus wind speed}

To further explore the difference between CSAT ver3 and ver4, we performed a test in the EOL wind tunnel with CSAT 0538 that was successively operated with ver3 and ver4. When the tunnel wind speed reaches around $20 \mathrm{~m} \mathrm{~s}^{-1}$, $T_{\mathrm{s}}$ from ver 4 was smaller than $T_{\text {ref }}$ by $0.5 \mathrm{~K}$, while $T_{\mathrm{s}}$ from ver3 was smaller than $T_{\text {ref }}$ by only $0.1 \mathrm{~K}$ (Fig. 7). This result is consistent with our NWT observations that $H_{\mathrm{CSAT}}$ for ver3 and ver4 behaves differently as wind speed increases (compare Fig. 2a and b).

To examine the possibility of errors in $T_{\mathrm{S}}$ on the NWT tower, we compare $T_{\mathrm{s}}^{\text {air }}$ to an aspirated temperature-humidity sensor $\left(T_{\text {asp }}\right)$ as a function of wind speed (Fig. 8). It is wellknown that $T_{\mathrm{s}}^{\text {air }}$ can contain a significant bias relative to true $T$ due to uncertainties in the sonic path length (Loescher et al., 2005; Mauder et al., 2007). Therefore, for presentation purposes, we adjusted $T_{\mathrm{s}}^{\text {air }}$ with an offset determined from the low wind speed value of $T_{\mathrm{s}}^{\text {air }}-T_{\text {asp }}$ (the offsets used for each CSAT are shown in Fig. 8). During both day and night and for ver3 and ver4 CSATs, $T_{\mathrm{s}}^{\text {air }}-T_{\text {asp }}$ shows a systematic decrease on the order of $0.2 \mathrm{~K}$ as wind speed increases from around 8 to $15 \mathrm{~m} \mathrm{~s}^{-1}$ (Fig. 8). This negative $T_{\mathrm{s}}^{\text {air }}$ error correlated with increasing $U$ explains the positive $H_{\mathrm{CSAT}}$ error in the NWT data (further details in Sect. 3.5). 
(a) 2007, 1 Jan - 31 Dec, Nighttime Data

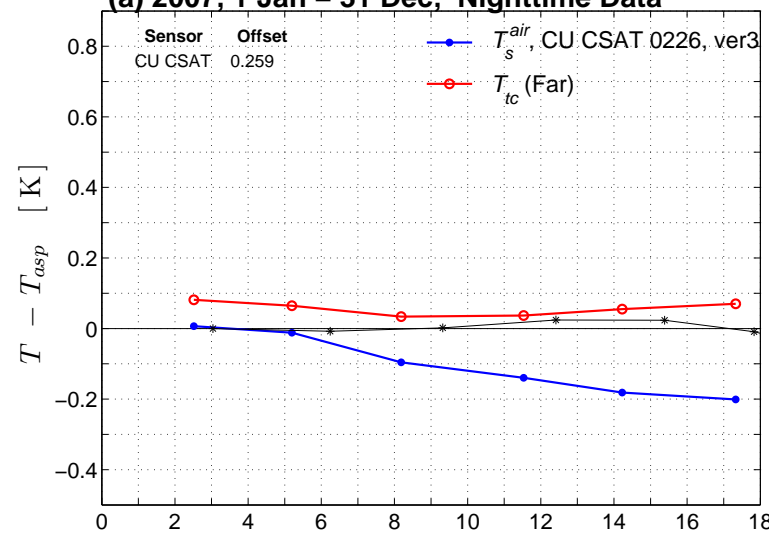

(c) 2007, 1 Jan - 31 Dec, Daytime Data

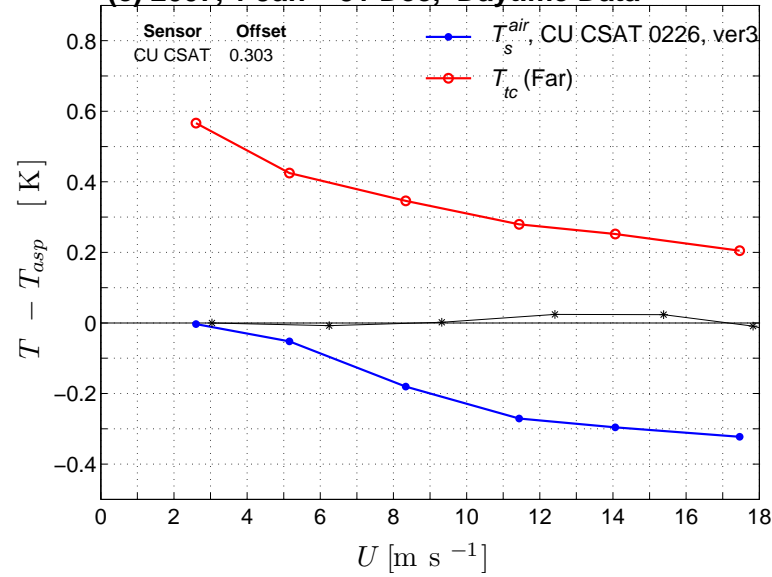

(b) 2010, 28 Sep - 31 Dec, Nighttime Data

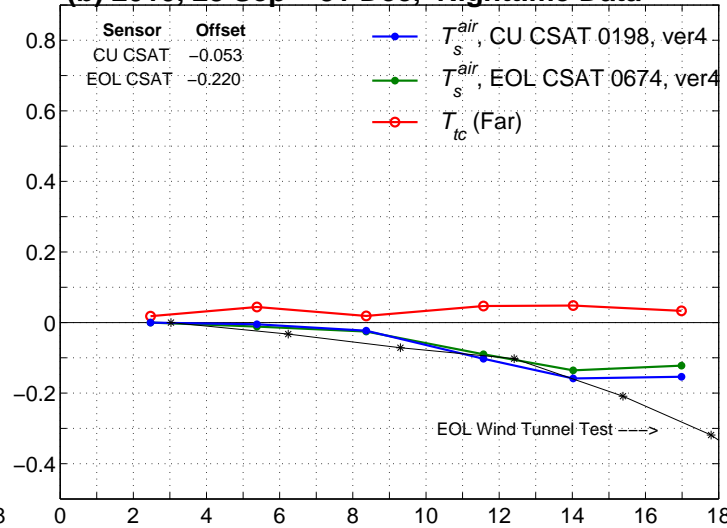

(d) 2010, 28 Sep - 31 Dec, Daytime Data

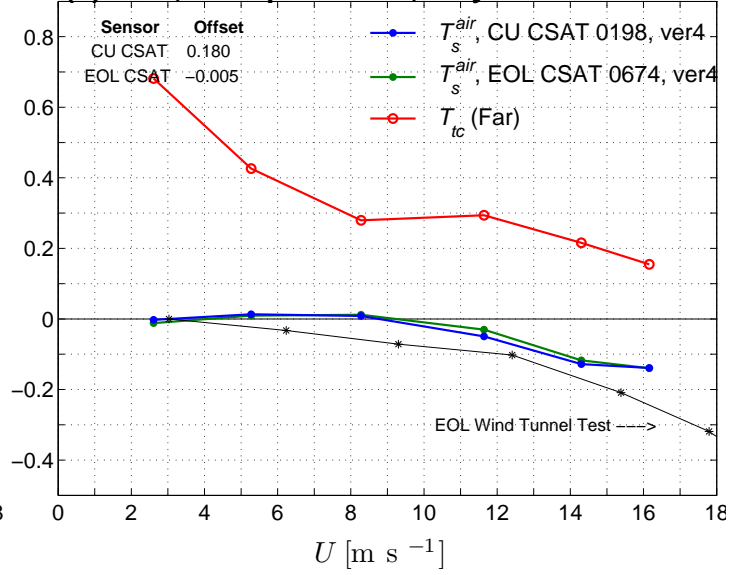

Fig. 8. The (a, b) nighttime and (c, d) daytime mean temperature difference $\left(T-T_{\text {asp }}\right)$ versus $21.5 \mathrm{~m}$ horizontal wind speed $U$. $T_{\text {asp }}$ is measured within a mechanically aspirated housing, and $T$ is from either a humidity-corrected CSAT $\left(T_{\mathrm{s}}^{\text {air }}\right)$ or a thermocouple $\left(T_{\mathrm{tc}}\right)$ as specified in the legend (also see Table 1). Only periods with $U>1 \mathrm{~m} \mathrm{~s}^{-1}$ are used. $T_{\mathrm{s}}^{\text {air }}$ has been adjusted to $T_{\text {asp }}$ using an offset determined for $1<U<4 \mathrm{~m} \mathrm{~s}^{-1}$, which is shown in the upper left corner of each panel. The time period used is shown above each panel. The black lines are the ver3 (left panels) and ver4 (right panels) wind tunnel data shown in Fig. 7.

The nighttime thermocouple measurements can be used to check the quality of the aspirated temperature-humidity measurements. At night (Fig. 8a and b), the $T_{\text {tc }}-T_{\text {asp }}$ difference is less than $\pm 0.1 \mathrm{~K}$ and independent of wind speed. However, during the day (Fig. 8c and d), there is a well-known radiation effect on $T_{\mathrm{tc}}$ that causes it to be larger than $T_{\mathrm{asp}}$ by about $0.6 \mathrm{~K}$ at low wind speeds but decreases to $0.2 \mathrm{~K}$ for high winds (e.g., Campbell, 1969; Burns and Sun, 2000; Foken, 2008b). Though $T_{\text {tc }}$ is affected by radiation, we note that the effect on $\overline{w^{\prime} T_{\text {tc }}^{\prime}}$ should be small because $w^{\prime}$ should not be correlated with the radiation error.

\subsection{Summary of Campbell Scientific, Inc. experiments}

To further test the sonic temperature issues, independent experiments were performed at Campbell Scientific, Inc. (CSI), and we provide a brief summary of the results here. In the future, CSI will release information with additional details and recommendations for CSAT users.
The CSI experiments identified the $T_{\mathrm{s}}$ errors to be caused by a delayed detection of the sonic pulse which is blown offaxis by high winds normal to the sonic-path. Delayed detection of the pulse arrival time results in an overestimation of the transit time which leads to an underestimation of the speed of sound and thus also sonic temperature (e.g., Eq. 3). Although this error is qualitatively similar to the correction for the crosswind component, it is quantitatively different and directly related to the firmware estimation of the pulse arrival time.

The CSI experiments also confirmed that the magnitude of the $T_{\mathrm{s}}$ errors differs for ver 3 and ver4 of the firmware. The CSI tests with a ver4 CSAT indicate that the issue occurs at all wind speeds, but is significant for $U>8 \mathrm{~m} \mathrm{~s}^{-1}$. With a newly calibrated ver3 CSAT, negligible temperature errors at high wind speeds were found (consistent with the measurements in the EOL wind tunnel as shown in Fig. 7). However, if a ver3 CSAT drifts out of calibration and crosses over a certain threshold, then $T_{\mathrm{S}}$ errors similar to the ver4 errors can 
(a) 2009, 27 Sep - 31 Dec, Nighttime Data

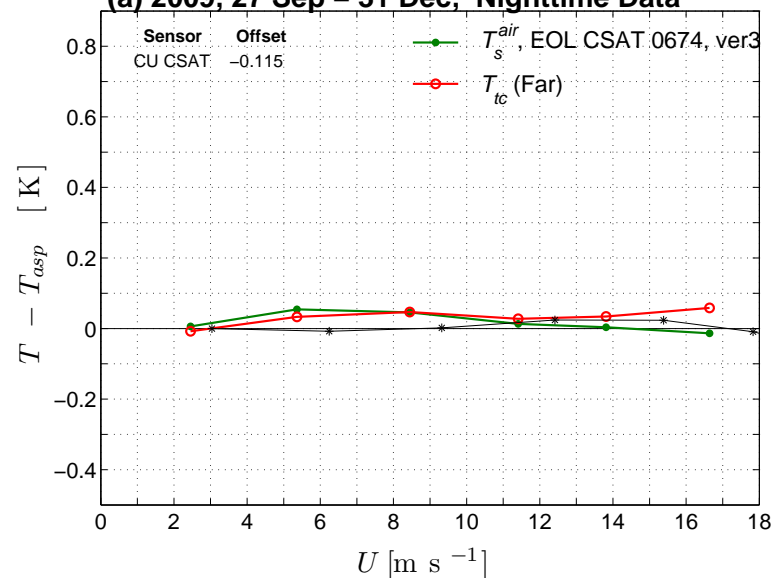

(b) 2011, 22 Oct - 31 Dec, Nighttime Data

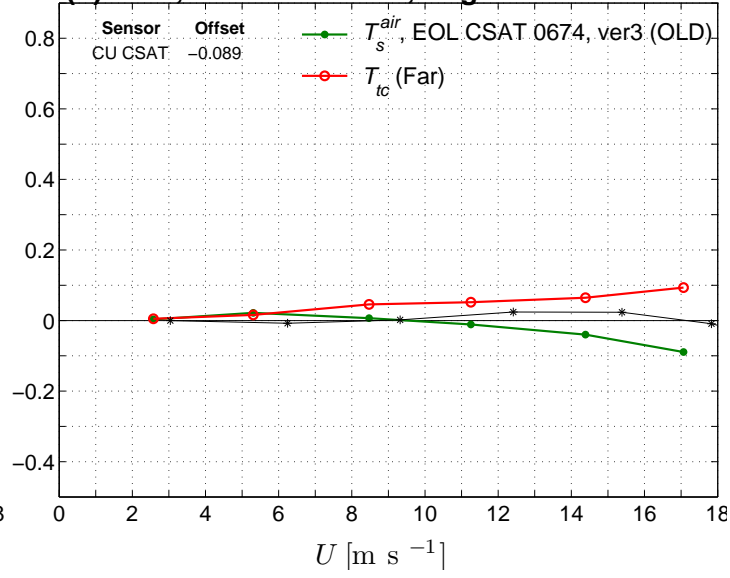

Fig. 9. As in Fig. 8, for the EOL CSAT 0674 ver3 using (a) newer and (b) older set of factory calibration coefficients. For details about the factory calibration dates, see Table 1 . Daytime data are not shown.

occur. The best indicator of calibration drift causing $T_{\mathrm{S}}$ errors in ver3 is the "poor signal lock" flag in the CSAT diagnostic output (Campbell Scientific, Inc., 2010). Although larger, the ver4 $T_{\mathrm{S}}$ errors are believed to be more stable with time than ver3 errors.

To explore how the age of the calibration affects the NWT tower data, in October 2011, we changed the EOL CSAT (ver3) to an older set of ver3 calibration coefficients (Table 1). There is a slight improvement in $T_{\mathrm{S}}-T_{\text {asp }}$ when the newer calibration coefficients were used (Fig. 9). We can also observe a small improvement in the $H_{\mathrm{CSAT}}-H_{T_{\mathrm{tc}}}$ difference (e.g., compare Fig. 2a to f).

The sonic temperature is significantly more sensitive to transit time errors than wind speed, because the wind components are calculated from the difference between transit times in opposite directions along the path (Foken, 2008b). The wind speed error due to the $T_{\mathrm{S}}$ error is estimated to be on the order of $0.1 \%$ at $20 \mathrm{~m} \mathrm{~s}^{-1}$ and $0.3 \%$ at $30 \mathrm{~m} \mathrm{~s}^{-1}$ and result in a slight underestimation of true wind speed.

\subsection{An empirical correction to $\boldsymbol{H}_{\mathrm{CSAT}}$}

A conceptual model of the CSAT heat flux error is that it depends on the covariance between vertical wind and erroneous fluctuations in the sonic temperature $\left(T_{\mathrm{err}}\right)$ :

$$
\frac{H_{\mathrm{err}}}{\bar{\rho} \overline{c_{\mathrm{p}}}}=\overline{w^{\prime} T_{\mathrm{err}}^{\prime}}=\overline{\left[\frac{\partial w}{\partial u} u^{\prime}\right]\left[\frac{\partial T_{\mathrm{err}}}{\partial u} u^{\prime}\right]}
$$

where $\partial w / \partial u$ is the slope of the relationship between vertical wind and the streamwise velocity component, and $\partial T_{\text {err }} / \partial u$ describes how the $T_{\mathrm{s}}$ error changes with respect to the streamwise velocity. To determine $\partial w / \partial u$, we could perform a least-squares fit of instantaneous $w$ and $u$ measurements over a 30-min period. However, the optimal slope of $\partial w / \partial u$ is also related to $\overline{u^{\prime} w^{\prime}}$ by

$$
\frac{\partial w}{\partial u}=\frac{\overline{u^{\prime} w^{\prime}}}{\overline{u^{\prime} u^{\prime}}}
$$

where $\overline{u^{\prime} u^{\prime}}$ is the variance of $u$. Because wind speed increases with height, $\overline{u^{\prime} w^{\prime}}$ is negative. To determine $\partial T_{\text {err }} / \partial u$, we used a polynomial fit of $T_{\mathrm{s}}^{\text {air }}-T_{\text {asp }}$ versus wind speed (e.g., Figs. 7 and 8) which is also negative. The two negative terms on the right side of Eq. (7) produce a positive heat flux error that is consistent with the NWT tower observations (i.e., $\overline{w^{\prime} T_{\mathrm{s}}^{\prime}}-\overline{w^{\prime} T_{\mathrm{tc}}^{\prime}}>0$ ). Substituting Eq. (8) into Eq. (7), the empirical expression for the $H_{\mathrm{CSAT}}$ error becomes

$$
\begin{aligned}
\frac{H_{\mathrm{err}}}{\bar{\rho} \overline{c_{\mathrm{p}}}} & =\left[\frac{\partial\left(A_{3} u^{3}+A_{2} u^{2}+A_{1} u+A_{0}\right)}{\partial u}\right] \overline{u^{\prime} w^{\prime}} \\
& =\left[3 A_{3} u^{2}+2 A_{2} u+A_{1}\right] \overline{u^{\prime} w^{\prime}},
\end{aligned}
$$

where $A_{3}, A_{2}, A_{1}$ and $A_{0}$ are empirical coefficients determined by a 3rd-order polynomial fit between $T_{\mathrm{s}}^{\text {air }}-T_{\text {asp }}$ and wind speed. The $H_{\mathrm{CSAT}}$ error determined with Eq. (9) is positive as expected (Fig. 10a). Furthermore, $H_{\mathrm{CSAT}}-H_{\mathrm{err}}$ is much closer to $H_{T_{\mathrm{tc}}}$ than $H_{\mathrm{CSAT}}$ (i.e., compare Fig. $10 \mathrm{~b}$ with Fig. 2d). This result shows how errors in the mean CSAT temperature are closely linked to the heat flux measurement errors. For some CSATs, a 2nd-order polynomial fit with Eq. (9) worked better than a 3rd-order fit (Fig. 10c). Other considerations when using Eq. (9) are the following: (1) the reference temperature sensor must not be significantly affected by changes in wind speed; (2) the coefficients $A_{3}-A_{0}$ are determined over a specific time period and will only be valid if the CSAT calibration does not significantly change; (3) if $\partial T_{\text {err }} / \partial u$ is stable with time, then an empirical correction can be used to correct historical fluxes measured by a particular CSAT; and (4) the $H_{\mathrm{CSAT}}$ error will be unique for each CSAT.

For the horizontal heat flux, $\overline{u^{\prime} w^{\prime}}$ in Eq. (9) gets replaced by $\overline{u^{\prime} u^{\prime}}$ so the sign of the horizontal heat flux error is negative (i.e., $\overline{u^{\prime} T_{\mathrm{s}}^{\prime}}-\overline{u^{\prime} T_{\mathrm{tc}}^{\prime}}<0$ ). Because $\overline{u^{\prime} w^{\prime}}<\overline{u^{\prime} u^{\prime}}$, the magnitude of the horizontal heat flux error is larger than the vertical heat flux error, consistent with our observations (not shown). 

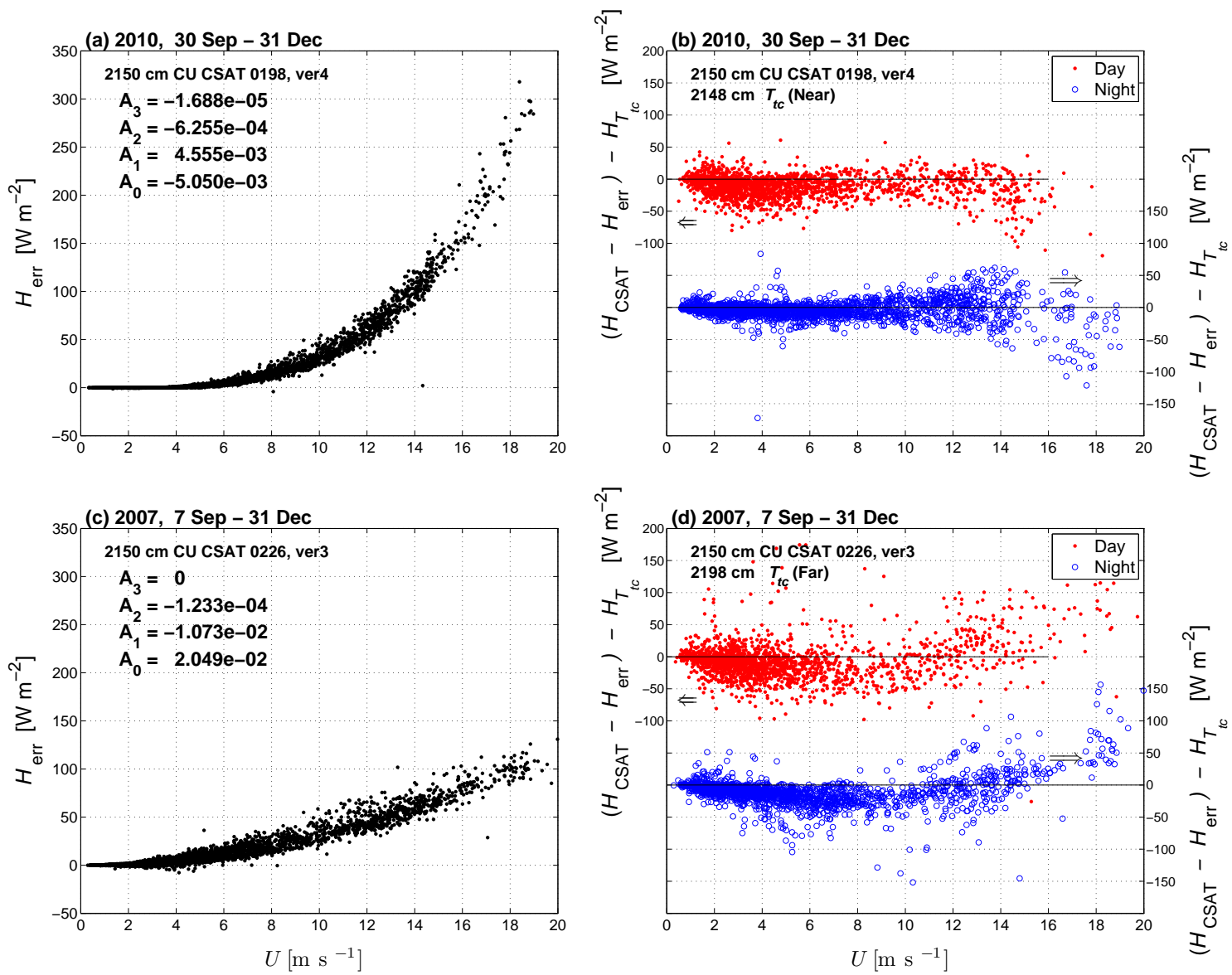

Fig. 10. The (a, c) $H_{\mathrm{CSAT}}$ sensible heat flux error $\left(H_{\mathrm{err}}\right)$ determined following Eq. $(9)$ and $(\mathbf{b}, \mathbf{d})\left(H_{\mathrm{CSAT}}-H_{\mathrm{err}}\right)-H_{T_{\mathrm{tc}}}$ difference versus the $21.5 \mathrm{~m}$ horizontal wind speed $U$ for a ver4 (upper panels) and ver3 (lower panels) CSAT. In (a, c), the coefficients $A_{3}-A_{0}$ are determined from a fit of $T_{\mathrm{s}}^{\text {air }}-T_{\mathrm{asp}}$ versus the wind speed. The difference shown in (b) and (d) can be compared to $H_{\mathrm{CSAT}}-H_{T_{\mathrm{tc}}}$ shown in Fig. $2 \mathrm{~d}$ and e, respectively. See the Fig. 2 caption for other details.

\subsection{Consideration of the surface energy balance}

As mentioned in the introduction, Turnipseed et al. (2002) found that the nocturnal SEB closure fraction during high winds varied between 0.2 and 0.6. In Fig. 11, closure fraction (CF, see Sect. 2.3 for details) is calculated using $H_{\mathrm{CSAT}}$ (CU 0226, ver3), $H_{\mathrm{CSAT}}$ empirically corrected with $H_{\text {err }}$ (i.e., Eq. 9), and $H_{T_{\mathrm{tc}}}$ (Far). As one would expect, CF with $H_{\mathrm{CSAT}}$ closely matches the results of Turnipseed et al. (2002). At night (Fig. $11 \mathrm{~b}$ ), CF peaks at $\approx 0.9$ for moderate wind speed, and then becomes negative as wind speed increases (or as friction velocity increases as shown in Fig. 7 of Turnipseed et al., 2002). For low winds, drainage flows form at the NWT site (Yi et al., 2005; Burns et al., 2011) and result in near-zero nocturnal $\mathrm{CF}$ values due to decoupling, strong horizontal advection of temperature, and practical difficulties with the flux calculation (e.g., Mahrt, 2010). These low-wind conditions require knowledge of horizontal advection for a more complete understanding (Sun et al., 2007; Yi et al., 2008).
During the day, closure fraction using $H_{T_{\mathrm{tc}}}$ and $H_{\mathrm{CSAT}}$ diverges at $U \approx 6 \mathrm{~m} \mathrm{~s}^{-1}$ (Fig. 11a). For $U>13 \mathrm{~m} \mathrm{~s}^{-1}$, CF with $H_{\text {CSAT }}$ is close to 1 . Knowing about the $H_{\mathrm{CSAT}}$ error in high winds (e.g., Fig. 3) suggests that the daytime $\mathrm{CF}$ approaching 1 is an artifact. In contrast, with $H_{T_{\mathrm{tc}}}$, both the daytime and nighttime $\mathrm{CF}$ values for $U>6 \mathrm{~m} \mathrm{~s}^{-1}$ are in reasonable agreement at $\mathrm{CF} \approx 0.65-0.75$, and there is almost no dependence of $\mathrm{CF}$ on wind speed. Unless there is a physical reason for CF to change in higher wind speeds, using $H_{T_{\mathrm{tc}}}$ appears more reasonable than $H_{\mathrm{CSAT}}$. With empirically corrected $H_{\mathrm{CSAT}}$, the day and night $\mathrm{CF}$ values in high winds are close to 1 and the dramatic wind speed-dependence is removed. Knowing that the far thermocouple underestimates the heat flux due to sensor separation (i.e., as discussed in Sect. 3.2), the SEB closure fraction at NWT, without considering the storage terms, is around $70-85 \%$. Taking into account the storage terms in Eq. (6), we would expect the CF to improve by another $5-10 \%$. Within complex terrain, radiation measurements are complicated (Oliphant et al., 2003) and the effect of sloping terrain on radiative fluxes needs to 

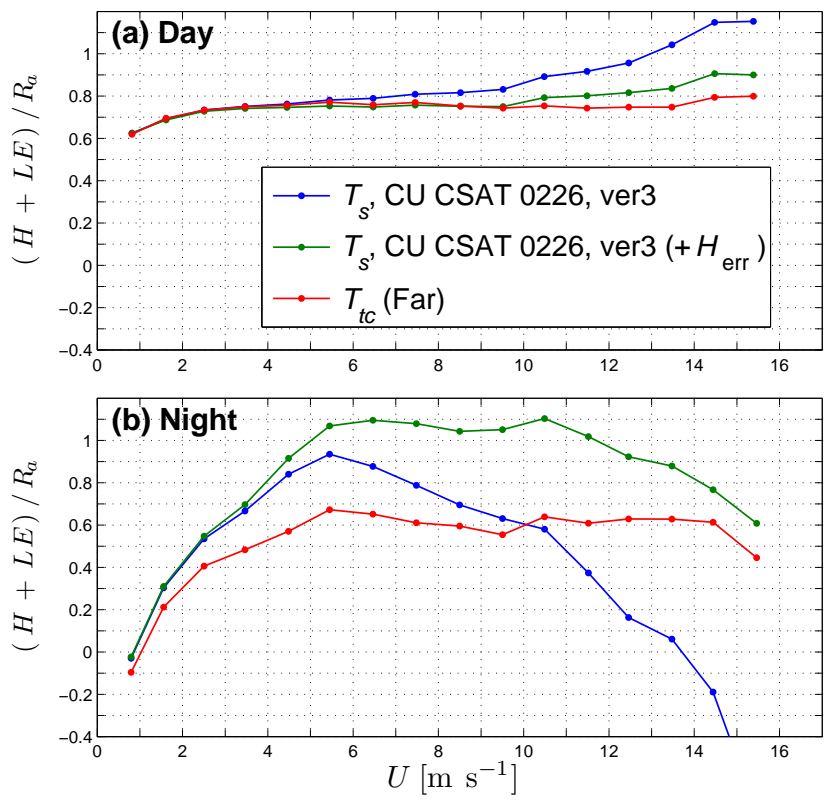

Fig. 11. The surface energy balance closure fraction $\left[\mathrm{CF}=(H+\mathrm{LE}) / R_{\mathrm{a}}\right]$ versus horizontal wind speed $U$ for years 2006-2007 for (a) daytime and (b) nighttime conditions ( $R_{\mathrm{a}}=R_{\text {net }}-G$ is the available energy; see text for details). $R_{\text {net }}$ is measured with a REBS, model $\mathrm{Q}^{* 7.1}$ radiometer. The temperature sensor used to calculate $H$ is specified in the legend. The calculation of $H_{\text {err }}$ for CSAT 0226 uses the coefficients shown in Fig. 10c. This figure is comparable to Fig. 7 in Turnipseed et al. (2002).

be taken into account (e.g., Leuning et al., 2012). Other factors that might cause the lack of closure are discussed elsewhere (e.g., Turnipseed et al., 2002; Foken et al., 2011; Leuning et al., 2012).

\section{Conclusions}

We compared sensible heat flux calculated using Campbell Scientific CSAT3 sonic anemometer temperature to heat flux calculated with a co-located thermocouple and found wind speed-dependent differences on the order of $250 \mathrm{~W} \mathrm{~m}^{-2}$ at high wind speeds $\left(H_{\mathrm{CSAT}}>H_{T_{\mathrm{tc}}}\right)$. These sensible heat flux differences have been traced to errors in CSAT sonic temperature that occur in high winds. Independent tests at Campbell Scientific, Inc. determined that the sonic temperature errors are due to delayed detection of the sound pulse (which is blown off-axis by high winds normal to the transducer path) leading to an overestimation of the pulse transit time and an underestimation of $T_{\mathrm{s}}$. Because the sound-pulse detection depends on the firmware, the error is firmware-dependent. The error is significant for ver4 of the firmware and much smaller or negligible for ver3 of the firmware (as long as the ver3 CSAT factory calibration is accurate). Using a polynomial fit of the $T_{\mathrm{S}}$ error as a function of wind speed, a conceptual model was tested and found to correct most of the $H_{\mathrm{CSAT}}$ error. Also consistent with the conceptual model, the CSAT horizontal heat flux error is larger than the vertical heat flux error and with opposite sign. Campbell Scientific, Inc. is currently working to better quantify the magnitude of the error and will mitigate it with future hardware and/or software changes.

We also considered the impact of the CSAT heat flux error on the closure fraction of the surface energy budget and found that using heat flux calculated with the thermocouple resulted in a more realistic closure fraction that was relatively insensitive to changes in wind speed. However, using spectral phase analysis, we observed that the time response of the thermocouple may lead to a slight underestimation of $H$. In the future, a fast response, fine-wire temperature sensor could be deployed for an additional check of heat flux from the thermocouple.

Though our study examines one specific model of sonic anemometer, it is recommended that any sonic anemometer deployed in a location with strong winds includes a fast-response temperature sensor to ensure accurate sensible heat flux measurements. Furthermore, in a broader context, our temperature comparison shows the added value of independent, co-located, in-situ measurements in environmental research. Previous comparisons of sonic anemometers by Loescher et al. (2005) were very thorough, but performed the comparison up to a wind speed of $\approx 6 \mathrm{~m} \mathrm{~s}^{-1}$, so any issues at higher wind speeds were undetected. This emphasizes an important advantage of long-term in-situ comparisons - they cover the range of the observation. In short, our study provides a practical example of how valuable in-situ comparisons can be in evaluating sensor performance.

Acknowledgements. We gratefully acknowledge assistance from the scientists and staff at Campbell Scientific, Inc., especially Edward Swiatek for his support and interest. Don Lenschow, Gordon Maclean, Steve Semmer, Jielun Sun and Steve Oncley provided useful discussions. We also thank Chris Golubieski (EOL CSAT and wind tunnel tests) and Jeff Beauregard (CU CSATs) for their assistance. Finally, we thank Erik Sahlée, Johannes Laubach, Thomas Foken, Heping Liu, Christof Ammann, and two anonymous reviewers for comments that greatly improved the paper. The NWT tower has been supported by grants from the South Central Section of the National Institute for Global Environmental Change (NIGEC) through the US Department of Energy (BER Program, Cooperative Agreement No. DE-FC03-90ER61010) and from the National Science Foundation (NSF) Long-Term Research in Environmental Biology (LTREB). The National Center for Atmospheric Research (NCAR) is sponsored by NSF.

Edited by: C. Ammann 


\section{References}

Aubinet, M., Grelle, A., Ibrom, A., Rannik, U., Moncrieff, J., Foken, T., Kowalski, A. S., Martin, P. H., Berbigier, P., Bernhofer, C., Clement, R., Elbers, J., Granier, A., Grunwald, T., Morgenstern, K., Pilegaard, K., Rebmann, C., Snijders, W., Valentini, R., and Vesala, T.: Estimates of the annual net carbon and water exchange of forests: The EUROFLUX methodology, Adv. Ecol. Res., 30, 113-175, 2000.

Barr, A. G., Morgenstern, K., Black, T. A., McCaughey, J. H., and Nesic, Z.: Surface energy balance closure by the eddy-covariance method above three boreal forest stands and implications for the measurement of the $\mathrm{CO}_{2}$ flux, Agr. Forest Meteorol., 140, 322337, 2006.

Benedict, R.: Fundamentals of Temperature, Pressure, and Flow Measurements, Wiley-Interscience publication, 2nd Edn., Wiley, New York, 517 pp., 1977.

Berg, N. H.: Blowing snow at a Colorado alpine site: Measurements and implications, Arct. Alpine Res., 18, 147-161, 1986.

Blanken, P. D., Black, T. A., Yang, P. C., Neumann, H. H., Nesic, Z., Staebler, R., den Hartog, G., Novak, M. D., and Lee, X.: Energy balance and canopy conductance of a boreal aspen forest: Partitioning overstory and understory components, J. Geophys. Res., 102, 28915-28927, 1997.

Blanken, P. D., Black, T. A., Neumann, H. H., Den Hartog, G., Yang, P. C., Nesic, Z., Staebler, R., Chen, W., and Novak, M. D.: Turbulent flux measurements above and below the overstory of a boreal aspen forest, Bound.-Lay. Meteorol., 89, 109-140, 1998.

Burns, S. P. and Sun, J.: Thermocouple temperature measurements from the CASES-99 main tower, in: Proceedings of the 14th Symposium on Boundary Layer and Turbulence, Amer. Meteor. Soc., Snowmass, Colorado, 7-11 August 2000, 358-361, 2000.

Burns, S. P., Sun, J., Lenschow, D. H., Oncley, S. P., Stephens, B. B., Yi, C., Anderson, D. E., Hu, J., and Monson, R. K.: Atmospheric stability effects on wind fields and scalar mixing within and just above a subalpine forest in sloping terrain, Bound.-Lay. Meteorol., 138, 231-262, doi:10.1007/s10546-010-9560-6, 2011.

Burns, S. P., Horst, T. W., Blanken, P. D., and Monson, R. K.: Using sonic anemometer temperature to measure sensible heat flux in strong winds, Atmos. Meas. Tech. Discuss., 5, 447-469, doi:10.5194/amtd-5-447-2012, 2012.

Campbell, G. S.: Measurement of air temperature fluctuations with thermocouples, Tech. Rep. ECOM-5273, Atmospheric Sciences Laboratory, White Sands Missile Range, 10 pp., 1969.

Campbell Scientific, Inc.: CSAT3 Three Dimensional Sonic Anemometer Manual (Revision 6/10), Campbell Scientific, Inc., Logan, Utah, 70 pp., 2010.

Farahmand, K. and Kaufman, J. W.: Experimental measurement of fine thermocouple response time in air, Exp. Heat Transfer, 14, 107-118, doi:10.1080/08916150120876, 2001.

Foken, T.: Bestimmung der Schneedrift mittels Ultraschallanemometern (Detection of snow drift with sonic anemometers), Ann. Meteorol., 37, 451-452, 1998.

Foken, T.: The energy balance closure problem: An overview, Ecol. Appl., 18, 1351-1367, 2008a.

Foken, T.: Micrometeorology, Springer, Heidelberg, 308 pp., $2008 \mathrm{~b}$.

Foken, T., Aubinet, M., Finnigan, J. J., Leclerc, M. Y., Mauder, M., and Paw U, K. T.: Results of a panel discussion about the energy balance closure correction for trace gases, B. Am. Meteorol. Soc., 92, ES13-ES18, 2011.
Franssen, H. J. H., Stöckli, R., Lehner, I., Rotenberg, E., and Seneviratne, S. I.: Energy balance closure of eddy-covariance data: A multisite analysis for European FLUXNET stations, Agr. Forest Meteorol., 150, 1553-1567, doi:10.1016/j.agrformet.2010.08.005, 2010.

Friebel, H. C., Herrington, T. O., and Benilov, A. Y.: Evaluation of the flow distortion around the Campbell Scientific CSAT3 sonic anemometer relative to incident wind direction, J. Atmos. Ocean. Tech., 26, 582-592, doi:10.1175/2008JTECHO550.1, 2009.

Friehe, C. A. and Khelif, D.: Fast-response aircraft temperature sensors, J. Atmos. Ocean. Tech., 9, 784-795, 1992.

Friehe, C. A., Shaw, W. J., Rogers, D. P., Davidson, K. L., Large, W. G., Stage, S. A., Crescenti, G. H., Khalsa, S. J. S., Greenhut, G. K., and Li, F.: Air-sea fluxes and surface-layer turbulence around a sea-surface temperature front, J. Geophys. Res., 96, 8593-8609, 1991.

Fuehrer, P. L. and Friehe, C. A.: Flux corrections revisited, Bound.Lay. Meteorol., 102, 415-457, 2002.

Fuehrer, P. L., Friehe, C. A., and Edwards, D. K.: Frequencyresponse of a thermistor temperature probe in air, J. Atmos. Ocean. Tech., 11, 476-488, 1994.

Garratt, J. R.: The Atmospheric Boundary Layer, Cambridge University Press, Cambridge, 316 pp., 1992.

Grelle, A. and Burba, G.: Fine-wire thermometer to correct $\mathrm{CO}_{2}$ fluxes by open-path analyzers for artificial density fluctuations, Agr. Forest Meteorol., 147, 48-57, 2007.

Grelle, A. and Lindroth, A.: Eddy-correlation system for long-term monitoring of fluxes of heat, water vapour and $\mathrm{CO}_{2}$, Global Change Biol., 2, 297-307, 1996.

Hignett, P.: Corrections to temperature-measurements with a sonic anemometer, Bound.-Lay. Meteorol., 61, 175-187, 1992.

Horst, T. W. and Lenschow, D. H.: Attenuation of scalar fluxes measured with spatially-displaced sensors, Bound.-Lay. Meteorol., 130, 275-300, 2009.

Kaimal, J. C. and Businger, J. A.: A continuous wave sonic anemometer-thermometer, J. Appl. Meteorol., 2, 156-164, 1963.

Kaimal, J. C. and Finnigan, J. J.: Atmospheric Boundary Layer Flows: Their Structure and Measurement, Oxford University Press, New York, 289 pp., 1994.

Kaimal, J. C. and Gaynor, J. E.: Another look at sonic thermometry, Bound.-Lay. Meteorol., 56, 401-410, 1991.

Lanzinger, E. and Langmack, H.: Measuring Air Temperature by using an Ultrasonic Anemometer, in: Technical Conference on Meteorological and Environmental Instruments and Methods of Observation (TECO-2005), WMO Tech. Doc. No. 1265; IOM Report No. 82, World Meteorological Organization, Geneva, Switzerland, p. P3(9), 2005.

Laubach, J.: Charakterisierung des turbulenten Austauschs von Wärme, Wasserdampf und Kohlendioxid über niedriger Vegetation anhand von Eddy-Korrelations-Messungen (Characterization of the turbulent exchange of heat, water vapor, and carbon dioxide over low vegetation by means of eddy correlation measurements), Ph.D. thesis, University of Leipzig, Leipzig, Germany, 1995.

Lenschow, D. H. and Sun, J.: The spectral composition of fluxes and variances over land and sea out to the mesoscale, Bound.Lay. Meteorol., 125, 63-84, 2007. 
Lenschow, D. H., Mann, J., and Kristensen, L.: How long is long enough when measuring fluxes and other turbulence statistics?, J. Atmos. Ocean. Tech., 11, 661-673, 1994.

Leuning, R., van Gorsel, E., Massman, W. J., and Isaac, P. R.: Reflections on the surface energy imbalance problem, Agr. Forest Meteorol., 156, 65-74, doi:10.1016/j.agrformet.2011.12.002, 2012.

Loescher, H. W., Ocheltree, T., Tanner, B., Swiatek, E., Dano, B., Wong, J., Zimmerman, G., Campbell, J., Stock, C., Jacobsen, L., Shiga, Y., Kollas, J., Liburdy, J., and Law, B. E.: Comparison of temperature and wind statistics in contrasting environments among different sonic anemometer-thermometers, Agr. Forest Meteorol., 133, 119-139, 2005.

Lüers, J. and Bareiss, J.: Direct near-surface measurements of sensible heat fluxes in the Arctic tundra applying eddy covariance and laser scintillometry - the Arctic Turbulence Experiment 2006 on Svalbard (ARCTEX-2006), Theor. Appl. Climatol., 105, 387402, doi:10.1007/s00704-011-0400-5, 2011.

Mahrt, L.: Computing turbulent fluxes near the surface: needed improvements, Agr. Forest Meteorol., 150, 501-509, 2010.

Massman, W. and Clement, R.: Uncertainty in eddy covariance flux estimates resulting from spectral attenuation, in: Handbook of Micrometeorology, edited by: Lee, X., Massman, W., and Law, B., vol. 29 of Atmospheric and Oceanographic Sciences Library, Springer Netherlands, 67-99, doi:10.1007/1-4020-22654_4, 2005.

Mauder, M., Oncley, S. P., Vogt, R., Weidinger, T., Ribeiro, L., Bernhofer, C., Foken, T., Kohsiek, W., De Bruin, H. A. R., and Liu, H.: The energy balance experiment EBEX-2000, Part II: Intercomparison of eddy-covariance sensors and post-field data processing methods, Bound.-Lay. Meteorol., 123, 29-54, 2007.

Monson, R. K., Turnipseed, A. A., Sparks, J. P., Harley, P. C., ScottDenton, L. E., Sparks, K., and Huxman, T. E.: Carbon sequestration in a high-elevation, subalpine forest, Global Change Biol., 8, 459-478, 2002.

Oliphant, A. J., Spronken-Smith, R. A., Sturman, A. P., and Owens, I. F.: Spatial variability of surface radiation fluxes in mountainous terrain, J. Appl. Meteorol., 42, 113-128, 2003.

Oncley, S. P., Foken, T., Vogt, R., Kohsiek, W., DeBruin, H. A. R., Bernhofer, C., Christen, A., van Gorsel, E., Grantz, D., Feigenwinter, C., Lehner, I., Liebethal, C., Liu, H., Mauder, M., Pitacco, A., Ribeiro, L., and Weidinger, T.: The Energy Balance Experiment EBEX-2000, Part I: Overview and energy balance, Bound.Lay. Meteorol., 123, 1-28, 2007.

Patton, E. G., Horst, T. W., Sullivan, P. P., Lenschow, D. H., Oncley, S. P., Brown, W. O. J., Burns, S. P., Guenther, A. B., Held, A., Karl, T., Mayor, S. D., Rizzo, L. V., Spuler, S. M., Sun, J., Turnipseed, A. A., Allwine, E. J., Edburg, S. L., Lamb, B. K., Avissar, R., Calhoun, R. J., Kleissl, J., Massman, W. J., Paw, K. T., and Weil, J. C.: The Canopy Horizontal Array Turbulence Study, B. Am. Meteorol. Soc., 92, 593-611, 2011.

Schotanus, P., Nieuwstadt, F. T. M., and De Bruin, H. A. R.: Temperature-measurement with a sonic anemometer and its application to heat and moisture fluxes, Bound.-Lay. Meteorol., 26, 81-93, 1983.
Smedman, A.-S., Högström, U., Sahlée, E., and Johansson, C.: Critical re-evaluation of the bulk transfer coefficient for sensible heat over the ocean during unstable and neutral conditions, Q. J. Roy. Meteorol. Soc., 133, 227-250, 2007.

Stewart, J. B. and Thom, A. S.: Energy budgets in pine forest, Q. J. Roy. Meteorol. Soc., 99, 154-170, 1973.

Stull, R. B.: An Introduction to Boundary Layer Meteorology, Kluwer Academic Publishers, Dordrecht, The Netherlands, 1988.

Sun, J., Burns, S. P., Delany, A. C., Oncley, S. P., Turnipseed, A. A., Stephens, B. B., Lenschow, D. H., LeMone, M. A., Monson, R. K., and Anderson, D. E.: $\mathrm{CO}_{2}$ transport over complex terrain, Agr. Forest Meteorol., 145, 1-21, doi:10.1016/j.agrformet.2007.02.007, 2007.

Timouk, F., Kergoat, L., Mougin, E., Lloyd, C. R., Ceschia, E., Cohard, J. M., de Rosnay, P., Hiernaux, P., Demarez, V., and Taylor, C. M.: Response of surface energy balance to water regime and vegetation development in a Sahelian landscape, J. Hydrol., 375, 178-189, 2009.

Turnipseed, A. A., Blanken, P. D., Anderson, D. E., and Monson, R. K.: Energy budget above a high-elevation subalpine forest in complex topography, Agr. Forest Meteorol., 110, 177-201, 2002.

Turnipseed, A. A., Anderson, D. E., Blanken, P. D., Baugh, W. M., and Monson, R. K.: Airflows and turbulent flux measurements in mountainous terrain. Part 1: canopy and local effects, Agr. Forest Meteorol., 119, 1-21, 2003.

Verma, S. B., Motha, R. P., and Rosenberg, N. J.: A comparison of temperature fluctuations measured by a microbead thermistor and a fine wire thermocouple over a crop surface, Agr. Meteorol., 20, 281-289, doi:10.1016/0002-1571(79)90002-5, 1979.

Wilczak, J. M., Oncley, S. P., and Stage, S. A.: Sonic anemometer tilt correction algorithms, Bound.-Lay. Meteorol., 99, 127-150, 2001.

Wilson, K., Goldstein, A., Falge, E., Aubinet, M., Baldocchi, D., Berbigier, P., Bernhofer, C., Ceulemans, R., Dolman, H., Field, C., Grelle, A., Ibrom, A., Law, B. E., Kowalski, A., Meyers, T., Moncrieff, J., Monson, R., Oechel, W., Tenhunen, J., Valentini, R., and Verma, S.: Energy balance closure at FLUXNET sites, Agr. Forest Meteorol., 113, 223-243, 2002.

Yi, C., Monson, R. K., Zhai, Z. Q., Anderson, D. E., Lamb, B., Allwine, G., Turnipseed, A. A., and Burns, S. P.: Modeling and measuring the nocturnal drainage flow in a high-elevation, subalpine forest with complex terrain, J. Geophys. Res., 110, D22303, doi:10.1029/2005JD006282, 2005.

Yi, C., Anderson, D. E., Turnipseed, A. A., Burns, S. P., Sparks, J. P., Stannard, D. I., and Monson, R. K.: The contribution of advective fluxes to net ecosystem exchange in a high-elevation, subalpine forest, Ecol. Appl., 18, 1379-1390, doi:10.1890/060908.1, 2008. 